NBER WORKING PAPER SERIES

\title{
CAN INFORMATION HETEROGENEITY EXPLAIN \\ THE EXCHANGE RATE DETERMINATION PUZZLE?
}

\author{
Philippe Bacchetta \\ Eric van Wincoop \\ Working Paper 9498 \\ http://www.nber.org/papers/w9498 \\ NATIONAL BUREAU OF ECONOMIC RESEARCH \\ 1050 Massachusetts Avenue \\ Cambridge, MA 02138 \\ February 2003
}

We would like to thank Gianluca Benigno, Margarida Duarte, Ken Froot, Richard Lyons, and seminar participants at the NBER IFM fall meeting, a CEPR-RTN workshop in Dublin, the New York Fed, the Board of Governors, CEMFI, and the Universities of Virginia and Lausanne for comments. Bacchetta's work on this paper is part of a research network on 'The Analysis of International Capital Markets: Understanding Europe's role in the Global Economy,' funded by the European Commission under the Research Training Network Program (Contract No. HPRN-CT-1999-00067). The views expressed herein are those of the authors and not necessarily those of the National Bureau of Economic Research.

(C2003 by Eric van Wincoop and Philippe Bacchetta. All rights reserved. Short sections of text not to exceed two paragraphs, may be quoted without explicit permission provided that full credit including notice, is given to the source. 
Can Information Heterogeneity Explain the Exchange Rate Determination Puzzle?

Philippe Bacchetta and Eric van Wincoop

NBER Working Paper No. 9498

February 2003

JEL No. F3, F4, G0, G1, E0

\section{$\underline{\text { ABSTRACT }}$}

Empirical evidence shows that macroeconomic fundamentals have little explanatory power for nominal exchange rates. On the other hand, the recent "microstructure approach to exchange rates" has shown that most exchange rate volatility at short to medium horizons is related to order flows. This suggests that investor heterogeneity might be key to understanding exchange rate dynamics, in contrast to the common representative agent approach in macroeconomic models of exchange rate determination. To explore this issue, we introduce investor heterogeneity into an otherwise standard monetary model of exchange rate determination. There are two types of heterogeneity: dispersed information about fundamentals and non-fundamentals based heterogeneity (e.g., liquidity traders). We show that information dispersion leads to magnification and endogenous persistence of the impact of non-fundamentals trade on the exchange rate, both resulting from rational confusion about the source of exchange rate fluctuations. Higher order expectations, familiar from Keynes' ' beauty contest", partly contribute to these results. The implications of the model are consistent with the evidence on the relationship between exchange rates and fundamentals: (i)fundamentals play little role in explaining exchange rate movements in the short to medium run, (ii) over longer horizons the exchange rate is primarily driven by fundamentals, (iii) exchange rate changes are a weak predictor of future fundamentals.

Eric van Wincoop

Department of Economics University of Virginia

Charlottesville, VA 22904

and NBER

vanwincoop@virginia.edu
Philippe Bacchetta

Study Center Gerzensee

3115 Gerzensee

Switzerland

bacchetta@szgerzensee.ch 


\section{Introduction}

The enormous volume of trade in the foreign exchange market, $\$ 1.2$ trillion per day in 2001, reflects extensive heterogeneity among market participants. Moreover, recent evidence from the microstructure approach to exchange rates suggests that investor heterogeneity is not a sideshow, but a critical driving force behind exchange rate fluctuations. In particular, Evans and Lyons [2001] show that most short-run exchange rate volatility is related to order flow, which in turn is associated with investor heterogeneity. ${ }^{1}$ On the other hand, existing macroeconomic models of exchange rate determination, in which there is no role for investor heterogeneity, have fared poorly. Meese and Rogoff [1983] found that a random walk predicts exchange rates better than macroeconomic models. Their findings remain valid today. ${ }^{2}$ Lyons [2001] refers to the weak explanatory power of macroeconomic fundamentals as the "exchange rate determination puzzle" and characterizes exchange rate economics as in a state of crisis. ${ }^{3}$ A natural question is whether investor heterogeneity can explain this puzzle.

The goal of this paper is to examine the impact of investor heterogeneity on exchange rate behavior. In order to do so in a way that is most transparent, we introduce investor heterogeneity into a standard monetary model of exchange rate determination. We introduce two types of heterogeneity that have generally been associated with order flow. The first type is heterogeneous information of market participants about future macroeconomic fundamentals. We know from extensive survey evidence that investors have different views about the macroeconomic outlook. ${ }^{4}$ The second type is non-fundamentals based heterogeneity. This includes noise traders, but more generally involves rational investors who trade

\footnotetext{
${ }^{1}$ See also Rime [2001] and Froot and Ramadorai [2002].

${ }^{2}$ More recently Cheung, Chinn, and Pascual [2002] consider a much wider range of models than originally considered by Meese and Rogoff and find that none of them consistently outperforms the random walk in predictive power. For a survey see Frankel and Rose [1995].

${ }^{3}$ The exchange rate determination puzzle is part of a broader set of exchange rate puzzles that Obstfeld and Rogoff [2001] have called the exchange rate disconnect puzzle. This also includes the lack of feedback from the exchange rate to the macro economy and the excess volatility of exchange rates (relative to fundamentals).

${ }^{4}$ There is also evidence that exchange rate expectations differ substantially across investors. See Chionis and MacDonald [2002], Ito [1990], Elliott and Ito [1999], and MacDonald and Marsh [1996].
} 
for non-speculative reasons. Examples are liquidity traders, trades resulting from hedging idiosyncratic endowment or preference shocks, or trades associated with differential access to private investment opportunities. ${ }^{5}$ Some recent papers have introduced the second type of heterogeneity into models of exchange rate determination, mostly in the form of noise traders, but they do not consider information dispersion. ${ }^{6}$ We will show that it is the interaction of these two types of heterogeneity that helps in understanding the exchange rate determination puzzle.

Our model is in the tradition of the noisy rational expectations literature, in which both types of heterogeneity are present. ${ }^{7}$ In that literature asset prices are an important source of information for investors as they aggregate private information of individual investors. Noise reduces the information content of asset prices, but is necessary for a rational expectations equilibrium to exist. ${ }^{8}$ Most noisy rational expectations models are static or two-period models. This makes them ill-suited to address the disconnect between asset prices and fundamentals, which is much stronger in the long-run than the short-run (e.g. Mark [1995] for exchange rates).

The problem with solving dynamic noisy rational expectations models with heterogeneous information is what Townsend [1983] called "infinite regress". Asset prices depend on higher order expectations of fundamentals: expectations of other investors' expectations, expectations of expectations of other investors' expectations, and so on. The dimension of these higher order expectations increases with the horizon, leading to infinite regress for an infinite horizon model. This is not a mere technical nuisance. Keynes [1936] compared investment decisions to a beauty contest, where "... each competitor has to pick, not those faces which he himself finds prettiest, but those which he thinks likeliest to catch the fancy of the other competitors...". In Keynes' view the market is very much driven by opinions of other investors' opinions, and even higher order than that.

\footnotetext{
${ }^{5}$ See respectively Dow and Gorton [1995], Spiegel and Subrahmanyam [1992] and Wang [1994].

${ }^{6}$ Examples are Jeanne and Rose [2002], Devereux and Engel [2002], Kollman [2002], and Mark and Wu [1998]. Hau and Rey [2002] introduce non-fundamentals based heterogeneity through an exogenous foreign exchange supply function of banks.

${ }^{7}$ Three influential papers that jump-started this literature are Grossman and Stiglitz [1980], Hellwig [1980] and Diamond and Verrecchia [1981]. For an overview, see Brunnermeier [2001].

${ }^{8}$ Without non-fundamentals noise the asset price fully reveals the aggregate information of all investors, so that they have no incentive to collect private information or to use it once they have collected it.
} 
There is a small literature that has studied dynamic noisy rational expectations models. He and Wang [1995] assume that an asset has one payoff at a terminal date. A continuous time version of that model has infinite regress, but an analytical solution is nonetheless feasible. However, the one-time payoff structure is less applicable to the foreign exchange market. Another approach is found in Wang [1993, 1994], who adopts a hierarchical information structure suggested by Townsend [1983]. A set of agents is fully informed, while another set of agents is uninformed. In that case higher order expectations collapse to first order expectations. ${ }^{9}$ Finally, Townsend [1983] develops a solution method for a model with symmetrically dispersed information. ${ }^{10}$ Townsend studies a dynamic business cycle model rather than an asset-pricing model. Subsequent contributions have been mostly technical, solving the same model as in Townsend [1983] with alternative methods. ${ }^{11}$ The only application to asset pricing we are aware of is Singleton [1987], who applies Townsend's method to a model for government bonds with a symmetric information structure. ${ }^{12}$

In this paper we adopt Townsend's symmetric information structure. This has two advantages over a hierarchical information structure. First, it allows us to focus on information dispersion itself rather than differences in the quality of information across investors. Second, when information is symmetrically dispersed,

\footnotetext{
${ }^{9}$ The expectation of a fundamental by an informed investor is the fundamental itself, so that the expectation by an uninformed investor of the expectation of an informed investor is equal to the first order expectation of the uninformed investor.

${ }^{10}$ The solution method described in Townsend [1983] applies to the model in section 8 of that paper where the economy-wide average price is observed with noise. Townsend [1983] mistakenly believed that higher order expectations are also relevant in a two-sector version of the model where firms observe each other's prices without noise. However, Pearlman and Sargent [2002] show that the equilibrium fully reveals private information in that case.

${ }^{11}$ See Kasa [2000] and Sargent [1991]. Probably as a result of the technical difficulty in solving these models, the macroeconomics literature has devoted relatively little attention to heterogeneous information in the last two decades. This contrasts with the 1970s where, following Lucas [1972], there had been active research on rational expectations and heterogeneous information (e.g., see King, 1982). Recently, information issues in the context of price rigidity have again been brought to the forefront in contributions by Woodford [2001] and Mankiw and Reis [2002].

${ }^{12}$ In Singleton's model there is no information dispersion about the payoff structure on the assets (in this case coupons on government bonds), but there is private information about whether non-fundamentals based trade (the noise) is transitory or persistent. The uncertainty is resolved after two periods.
} 
higher order expectations play an important role. In solving the model we adopt two alternative approaches. The first is Townsend's solution method. This gives an exact solution, but it can only be applied to asset pricing models with overlapping two-period lived investors (as in Singleton [1987]). The second approach is a close numerical approximation that we develop for the solution of the model with infinitely lived agents. This leads to almost identical results as applying the Townsend method to the case of two-period lived investors.

Introducing information heterogeneity helps in understanding the exchange rate determination puzzle along three dimensions. First, we show that a small amount of non-fundamentals based trade can become the dominant source of exchange rate volatility when information is heterogeneous, while it has practically no effect on the exchange rate when investors have common information. The reason is that under heterogeneous information the exchange rate itself becomes an important source of information about future fundamentals. The impact of non-fundamentals trade on the exchange rate can then be significantly amplified as agents rationally misinterpret the resulting exchange rate movements as information about future fundamentals. ${ }^{13}$ Moreover, as Allen, Morris and Shin [2003] have shown, asset prices are more sensitive to public information when they depend on higher order expectations. In this paper we show that higher order expectations give more weight to the exchange rate as a source of information, contributing to the magnification of the impact of non-fundamentals trade on the exchange rate.

Second, the resulting rational confusion can be persistent, which generates endogenous persistence of the impact of non-fundamentals based trade on the exchange rate. Finally, consistent with empirical evidence (e.g., Mark [1995]), the exchange rate is largely driven by fundamentals in the long run. As agents gradually learn about future fundamentals, and even observe them as time goes on, the rational confusion eventually dissipates. ${ }^{14}$

The remainder of the paper is organized as follows. Section II describes the

\footnotetext{
${ }^{13}$ In the context of static models, several authors, e.g., Gennotte and Leland [1990] and Romer [1993], argued that such rational confusion played a critical role in amplifying non-informational trade during the stock-market crash of October 19, 1987.

${ }^{14}$ Another recent paper on exchange rate dynamics where learning plays an important role is Gourinchas and Tornell [2002]. In that paper, in which there is no investor heterogeneity, agents learn about the nature of interest rate shocks (transitory or persistent), but there is an irrational misperception about the second moments in interest rate forecasts that never goes away.
} 
model and solution method. Section III considers some special cases of the model in order to develop intuition for our key results. Section IV presents the results based on the general dynamic model and Section $\mathrm{V}$ concludes.

\section{A Monetary Model with Information Disper- sion}

\section{II.A Infinite Regress}

Our model contains the three basic building blocks of the standard monetary model of exchange rate determination: (i) money market equilibrium, (ii) purchasing power parity, and (iii) interest rate parity. We modify the standard monetary model in two ways. First, we introduce non-fundamentals based trade, which affects the risk-premium in the interest parity condition. We model nonfundamentals trade in the form of noise traders, both because this is the easiest way to do it and because it has become a relatively standard way to model nonfundamentals trade in open economy macroeconomics. As emphasized in the introduction though, non-fundamentals based trade can be modeled in many ways and in general can be perfectly rational. We do not believe that our particular way of modeling it here is critical to the results. ${ }^{15}$ Second, we assume that investors have heterogeneous expectations about future fundamentals. Before describing the precise information structure, we first derive a general solution to the exchange rate under heterogeneous information, in which the exchange rate depends on higher order expectations of future fundamentals. This generalizes the standard equilibrium exchange rate equation that depends on (common) expectations of future fundamentals.

There are two economies. They produce the same good, so that purchasing power parity holds:

$$
p_{t}=p_{t}^{*}+s_{t}
$$

Local currency prices are in logs and $s_{t}$ is the log of the nominal exchange rate. ${ }^{16}$

\footnotetext{
${ }^{15}$ For example, the model in Wang [1993] is very similar to that in Wang [1994]. In the former the non-fundamentals trade is exogenous, while in the latter it is generated endogenously by giving some investors access to private investment opportunities.

${ }^{16}$ This assumption is relaxed in section IV.C when we introduce price stickiness.
} 
There is a continuum of investors in both countries on the interval $[0,1]$. We assume that there are overlapping generations of agents that live for two periods and make only one investment decision. This assumption significantly simplifies the presentation, helps in providing intuition, and allows us to obtain an exact solution to the model. However, it is not critical for the results and we discuss below the case where agents have infinite horizons.

Investors in both economies can invest in four assets: domestic money, nominal bonds of both countries with interest rates $i_{t}$ and $i_{t}^{*}$, and a technology with fixed real return $r$ that is in infinite supply. We assume that one economy is large and the other infinitesimally small. Bond market equilibrium is therefore entirely determined by investors in the large country, on which we will focus. We also assume that money supply in the large country is constant, which in equilibrium leads to a constant price level $p_{t}$, so that we can focus on nominal returns and $i_{t}=r$. Money supply in the small country is stochastic.

The wealth $w_{t}^{i}$ of investors born at time $t$ is given by a fixed endowment. At time $t+1$ these investors receive the return on their investments plus income from time $t+1$ production. We assume that production depends on real money holdings $\widetilde{m}_{t}^{i}$ through the function $f\left(\widetilde{m}_{t}^{i}\right)=k-\widetilde{m}_{t}^{i}\left(\ln \left(\widetilde{m}_{t}^{i}\right)-1\right) / \alpha{ }^{17}$ Agent $i$ maximizes

$$
-E_{t} e^{-\gamma c_{t+1}^{i}}
$$

subject to

$$
c_{t+1}^{i}=\left(1+i_{t}\right) w_{t}^{i}+\left(s_{t+1}-s_{t}+i_{t}^{*}-i_{t}\right) b_{t}^{i}-i_{t} \widetilde{m}_{t}^{i}+f\left(\widetilde{m}_{t}^{i}\right)
$$

where $w_{t}^{i}$ is real wealth at the start of period $t$, and $b_{t}^{i}$ is invested in foreign bonds. $s_{t+1}-s_{t}+i_{t}^{*}-i_{t}$ is the log-linearized excess return on investing abroad.

Combining the first order condition for money holdings with money market equilibrium in both countries we get

$$
\begin{aligned}
m_{t}-p_{t} & =-\alpha i_{t} \\
m_{t}^{*}-p_{t}^{*} & =-\alpha i_{t}^{*}
\end{aligned}
$$

where $m_{t}$, and $m_{t}^{*}$ are the logs of domestic and foreign nominal money supply. ${ }^{18}$

\footnotetext{
${ }^{17} \mathrm{By}$ introducing money through production rather than utility we avoid making money demand a function of consumption, which would complicate the solution.

${ }^{18}$ It is immediately clear that the equilibrium price level in the large country is constant since $i_{t}=r$ is constant and the money supply is constant.
} 
The demand for foreign bonds by investor $i$ is:

$$
b_{t}^{i}=\frac{E_{t}^{i}\left(s_{t+1}\right)-s_{t}+i_{t}^{*}-i_{t}}{\gamma \sigma_{t}^{2}}
$$

where $E_{t}^{i}\left(s_{t+1}\right)$ is the expectation of investor $i$.

We assume that a proportion $n$ of investors have a noisy expected return. More specifically, investors on the interval $[0,1-n]$ have rational expectations about the excess return on foreign bonds, while investors on the interval $[1-n, 1]$ have an error term $\chi_{t}$ added to the rational expectation. As is standard, we assume that $\operatorname{var}_{t}\left(s_{t+1}\right)=\sigma_{t}^{2}$ is rational for all traders. The net supply of foreign bonds resulting from the expectational error is given by $b_{t} \equiv-n \chi_{t} / \gamma \sigma_{t}^{2}$. We assume that $b_{t}$ follows an $\operatorname{AR}(1)$ process:

$$
b_{t}=\rho_{b} b_{t-1}+\varepsilon_{t}^{b}
$$

where $\varepsilon_{t}^{b} \sim N\left(0, \sigma_{b}^{2}\right)$. A critical assumption is that $b_{t}$ is not observable. ${ }^{19}$ Only the process is known to all agents.

Since bonds are in zero net supply, aggregation of (4) yields the following interest arbitrage condition:

$$
\bar{E}_{t}\left(s_{t+1}\right)-s_{t}=i_{t}-i_{t}^{*}+\gamma b_{t} \sigma_{t}^{2}
$$

where $\bar{E}_{t}$ is the average rational expectation across all investors. For noise traders it only includes the rational component of their expectation.

The model is summarized by (1), (2), (3), and (6). Other than the risk-premium in the interest rate parity condition associated with non-fundamentals trade, these equations are the standard building blocks of the monetary model of exchange rate determination.

Defining the fundamental as $f_{t}=\left(m_{t}-m_{t}^{*}\right)$, in Appendix A we derive the following equilibrium exchange rate:

$$
s_{t}=\frac{1}{1+\alpha} \sum_{k=0}^{\infty}\left(\frac{\alpha}{1+\alpha}\right)^{k} \bar{E}_{t}^{k}\left(f_{t+k}-\alpha \gamma \sigma_{t+k}^{2} b_{t+k}\right)
$$

where $\bar{E}_{t}^{0}\left(x_{t}\right)=x_{t}, \bar{E}_{t}^{1}\left(x_{t+1}\right)=\bar{E}_{t}\left(x_{t+1}\right)$ and higher order expectations are defined as

$$
\bar{E}_{t}^{k}\left(x_{t+k}\right)=\bar{E}_{t} \bar{E}_{t+1} \ldots \bar{E}_{t+k-1}\left(x_{t+k}\right) .
$$

\footnotetext{
${ }^{19}$ This is even the case for the irrational agents. Otherwise they would know their own expectational error.
} 
Thus, the exchange rate at time $t$ depends on the fundamental at time $t$, the average expectation of the fundamental at time $t+1$, the average expectation of the average expectation of the fundamental at $t+2$, etc. The law of iterated expectations does not apply to average expectations. For example, $\bar{E}_{t} \bar{E}_{t+1}\left(s_{t+2}\right) \neq \bar{E}_{t}\left(s_{t+2}\right) .{ }^{20}$ This is a basic feature of asset-pricing under heterogeneous expectations: the expectation of other investors' expectations matters. In a dynamic system, this leads to the infinite regress problem, as analyzed in Townsend [1983]: as the horizon goes to infinity the dimensionality of the expectation term goes to infinity.

\section{II.B The Information Structure}

We assume that investors receive a signal at time $t$ about the fundamental at $t+T$. We will compare the results under common knowledge, where all investors receive the same signal, to that under private (heterogeneous) information, where investors receive different signals. We define the fundamental $T$ periods from now as

$$
u_{t}=f_{t+T}
$$

With common knowledge all investors receive the signal

$$
v_{t}=u_{t}+\varepsilon_{t}^{v} \quad \varepsilon_{t}^{v} \sim N\left(0, \sigma_{v, c}^{2}\right)
$$

where $\varepsilon_{t}^{v}$ is independent of $u_{t}$. Under heterogeneous information investor $i$ receives a signal

$$
v_{t}^{i}=u_{t}+\varepsilon_{t}^{v i} \quad \varepsilon_{t}^{v i} \sim N\left(0, \sigma_{v}^{2}\right)
$$

where $\varepsilon_{t}^{v i}$ is independent from $u_{t}$ and other agents' signals. Due to the law of large numbers, the average signal received by investors is $u_{t}$, i.e., $\int_{0}^{1} v_{t}^{i} d i=u_{t}$.

We assume that the fundamental's process is always common knowledge to all agents:

$$
u_{t}=\rho_{1} u_{t-1}+\rho_{2} u_{t-2}+\varepsilon_{t}^{u} \quad \varepsilon_{t}^{u} \sim N\left(0, \sigma_{u}^{2}\right)
$$

Since investors observe current and lagged values of the fundamental, knowing the process provides information about the fundamental at future dates. The main

\footnotetext{
${ }^{20}$ This point is developed further below. See also Allen, Morris, and Shin [2002] for a discussion in a simpler setting.
} 
results of the paper, reported in section IV, are based on the assumption that $\rho_{1}=1+\rho$ and $\rho_{2}=-\rho$, so that the fundamental follows an AR process in first differences: $u_{t}-u_{t-1}=\rho\left(u_{t-1}-u_{t-2}\right)+\varepsilon_{t}^{u}$. We will take up the much simpler case where $\rho_{1}=\rho_{2}=0$ in the next section.

\section{II.C Solution Methods}

The model only has an analytical solution for the special case where $T=1$, which is discussed in the next section. In that case higher order expectations are equal to the average expectation and there is no infinite regress problem. This can be understood as follows. When $T=1$, investors do not use information from previous periods to update their expectations since the new information at time $t$ is the fundamental $f_{t}$ (which is obviously superior to any previous private signals about $f_{t}$ ). Thus, at time $t$ an investor should not expect his own expectation at $t+1$ to be different from that of others. Therefore the second order expectation is equal to the average expectation. The same is the case for even higher order expectations.

In the more general setup where $T>1$, investors do use information from previous periods to update their expectations. For example, private information at time $t$ affects time $t+1$ expectations of future fundamentals. In that case investors at time $t$ expect their own expectation at $t+1$ to be different from that of other investors, since they expect others to have received a different signal at time $t$. The expectation of signals by other investors is the expectation of $u_{t}$, which is generally different from the investor's own signal. When investors expect their own expectation next period to differ from that of others, the second order

expectation is not equal to the average expectation. The same is the case for even higher order expectations.

Townsend [1983] points out that the state space becomes infinite when there are infinitely many higher order expectations. He proposes an exact solution method when the number of unknown shocks is finite. Here we provide a brief description of the application to our model, leaving details to Appendix D. One can write down a Wold representation of the equilibrium exchange rate as

$$
s_{t}=A(L) \varepsilon_{t}^{u}+B(L) \varepsilon_{t}^{b}
$$

where $A(L)$ and $B(L)$ are infinite order polynomials in the lag operator $L$. The 
errors $\varepsilon_{t}^{i v}$ do not enter the exchange rate equation as they average to zero across investors. Since at time $t$ investors observe the fundamental $f_{t}$, only the new innovations $\varepsilon^{u}$ between time $t-T+1$ and time $t$ are unknown. The same is true for innovations to non-fundamentals trade. Exchange rates at time $t-T$ and earlier, together with knowledge of $\varepsilon^{u}$ at time $t-T$ and earlier, reveal the shocks $\varepsilon^{b}$ at time $t-T$ and earlier.

Investors can then solve a signal extraction problem for the finite number of unknown innovations. Both private signals and exchange rates from time $t-T+1$ to $t$ provide information about the innovations. The solution to the signal extraction problem leads to expectations at time $t$ of the unknowns as a function of observables, which in turn can be written as a function of the innovations themselves. One can then compute the average expectation of $s_{t+1}$. Substituting the result into the interest parity condition (6) leads to a new exchange rate equation. The coefficients of the polynomials $A(L)$ and $B(L)$ can then be derived by solving a fixed point problem, equating the coefficients of the conjectured exchange rate equation when solving the signal extraction problem to those in the equilibrium exchange rate equation. Although the lag polynomials are of infinite order, for lags longer than $T$ periods the information dispersion plays no role and an analytical solution to the coefficients is feasible.

The Townsend method cannot be applied when investors have infinite horizons. In that case investors maximize

$$
-E_{t}\left(\sum_{s=0}^{\infty} \beta^{s} e^{-\gamma c_{t+s}^{i}}\right)
$$

subject to

$$
w_{t+1}^{i}=\left(1+i_{t}\right) w_{t}^{i}+\left(s_{t+1}-s_{t}+i_{t}^{*}-i_{t}\right) b_{t}^{i}-i_{t} \tilde{m}_{t}^{i}+f\left(\widetilde{m}_{t}^{i}\right)-c_{t}^{i}
$$

Appendix E provides a detailed solution method for this problem. The portfolio maximization problem is now substantially more complicated and the interest rate parity condition needs to be modified. Investors now need to take into account uncertainty about future expected returns, and therefore future investment opportunities. They hedge against this risk when choosing their portfolio, but this hedge term depends on the infinite state space, which complicates matters. We obtain a close approximate solution by truncating the state space for sufficiently long lags. 
To be precise, let the state space of observables for an investor $i$ be $\mathbf{s}_{t-1}, \mathbf{f}_{t}$ and $\mathbf{v}_{t}^{i}$, where $\mathbf{x}_{t}=\left\{x_{t}, x_{t-1}, \ldots\right\}^{\prime}$. The aggregate of the private signals is $u$, so that $\int_{0}^{1} \mathbf{v}_{t}^{i}=\mathbf{u}_{t}$. We then conjecture the following equilibrium exchange rate equation as a function of the aggregate state space and the supply shock $b_{t}$ :

$$
s_{t}=\lambda_{s} \mathbf{s}_{t-1}+\lambda_{f} \mathbf{f}_{t}+\lambda_{u} \mathbf{u}_{t}+\lambda_{b} b_{t}
$$

We truncate the state space for lags more than $\bar{T}(>T)$. Coefficients in the exchange rate equation for longer lags are set equal to zero. In our benchmark case where $T=8$, setting $\bar{T}=25$ turns out to be sufficient. A larger $\bar{T}$ leaves results virtually unchanged. We solve the portfolio maximization problem by maximizing a Bellman equation, using both the conjectured exchange rate equation and a conjectured value function. The latter depends on the investor's wealth and a quadratic function of the investor's truncated state space. In solving the portfolio maximization problem we need to know the expectations of the unknowns $u_{t}, . ., u_{t-T+1}, b_{t}$ as a function of the investor's state space, which we compute through a Kalman filter technique. The conjectured exchange rate equation is again equated to the equilibrium exchange rate equation that follows from the asset market equilibrium. We also have to solve a fixed point problem for the parameters of the conjectured value function. All details can be found in the Appendix. We show in the Appendix that results based on this approximate solution technique for infinite horizon investors are almost identical to those based on applying the Townsend technique to the model with overlapping generations of investors. The results reported in section IV are based on the latter.

\section{The Impact of Information Dispersion}

In this section we examine the channels through which lack of common knowledge disconnects the exchange rate from its fundamental determinants. We will show that information heterogeneity leads to both magnification and endogenous persistence of the impact of non-fundamentals trade on the exchange rate. We first illustrate the magnification effect for the case $T=1$, where there is no infinite regress and the model has an analytical solution. We then show that higher order expectations further raise the magnification effect when they differ from simple average expectations. This is the case for $T>1$. Finally, we show that for $T>1$ 
there is endogenous persistence of the impact of non-fundamentals shocks on the exchange rate.

\section{III.A Magnification}

In addition to assuming $T=1$, so that there is no infinite regress problem, we further simplify by setting $\rho_{1}=\rho_{2}=0$ and $\rho_{b}=0$. In this case, equation (7) becomes:

$$
s_{t}=\frac{1}{1+\alpha}\left[f_{t}+\frac{\alpha}{1+\alpha} \bar{E}_{t} u_{t}\right]-\frac{\alpha}{1+\alpha} \gamma \sigma_{t}^{2} b_{t}
$$

Only the average expectation of $u_{t}$ appears, which is next period's fundamental. All higher order expectations are zero in this case. ${ }^{21}$

\section{III.A.1 Common knowledge}

As a benchmark, we first consider the case where all investors receive the same information. They have two pieces of information about $u_{t}$ : the signal $v_{t}=u_{t}+\varepsilon_{t}^{v}$ and the fact that $u_{t}=\varepsilon_{t}^{u}$. Defining the precision of these signals as $\beta^{v, c} \equiv 1 / \sigma_{v, c}^{2}$ and $\beta^{u} \equiv 1 / \sigma_{u}^{2}$, the conditional expectation of $u_{t}$ is

$$
E_{t}^{i} u_{t}=\bar{E}_{t} u_{t}=\frac{\beta^{v, c} v_{t}}{d}
$$

where $d \equiv 1 / \operatorname{var}_{t}\left(u_{t}\right)=\beta^{v, c}+\beta^{u}$. Substitution into (16) yields the equilibrium exchange rate:

$$
s_{t}=\frac{1}{1+\alpha} f_{t}+\lambda_{v} v_{t}+\lambda_{b, t}^{c} b_{t}
$$

where

$$
\begin{aligned}
\lambda_{v} & =\frac{\alpha}{(1+\alpha)^{2}} \frac{\beta^{v, c}}{d} \\
\lambda_{b, t}^{c} & =-\frac{\alpha}{1+\alpha} \gamma \sigma_{t}^{2}
\end{aligned}
$$

In addition to the observable fundamental, $f_{t}$, both the signal, $v_{t}$, and the non-fundamental factor, $b_{t}$, affect the exchange rate. Notice that in this case the exchange rate is fully revealing, since by observing $s_{t}$ investors can perfectly deduce $b_{t}$.

\footnotetext{
${ }^{21}$ If we allow for some persistence in the fundamental, higher order expectations are not zero, but still equal to average expectations of future fundamentals.
} 
The weight of the signal naturally depends on its precision $\beta^{v, c}$. The weight of the $b_{t}$ shock depends on $\sigma_{t}^{2}=\operatorname{var}_{t}\left(s_{t+1}\right)$, the conditional variance of next period's exchange rate. We show in Appendix B that there are two steady-states values for $\sigma_{t}^{2}$, but only one (the low value) is well defined. Hence, we focus on the low $\sigma^{2}$ steady state. This implies that the coefficient $\lambda_{b, t}^{c}$ is constant, $\lambda_{b, t}^{c}=\lambda_{b}^{c}$.

\section{III.A.2 Heterogeneous Information}

We now assume that investors get private signals $v_{t}^{i}$ about $u_{t}$ as given in (10). Due to the law of large numbers the aggregation of private signals is $u_{t}$, which implies that the exchange rate will be affected directly by $u_{t}$. Therefore, individual investors get information about $u_{t}$ by observing the exchange rate $s_{t}$. However, the exchange rate is not fully revealing, as it gives information about a combination of $u_{t}$ and $b_{t}$. To determine the information given by $s_{t}$, we need to know the equilibrium exchange rate equation. By analogy to (18), the investor conjectures that:

$$
s_{t}=\frac{1}{1+\alpha} f_{t}+\lambda_{u} u_{t}+\lambda_{b} b_{t}
$$

Since an investor observes $f_{t}$, the signal he gets from the exchange rate can be written

$$
\left(s_{t}-\frac{f_{t}}{1+\alpha}\right) / \lambda_{u}=u_{t}+\frac{\lambda_{b}}{\lambda_{u}} b_{t}
$$

The variance of this signal is $\left(\lambda_{b} / \lambda_{u}\right)^{2} \sigma_{b}^{2}$. Consequently, investor $i$ infers $E_{t}^{i} u_{t}$ from three sources of information: i) the distribution of $u_{t}$; ii) the signal $v_{t}^{i}$; iii) the exchange rate (i.e., (22)). As usual, $E_{t}^{i} u_{t}$ is given by a weighted average of the three signals, with the weights determined by the precision of each signal. We have:

$$
E_{t}^{i} u_{t}=\frac{\beta^{v} v_{t}^{i}+\beta^{s}\left(s_{t}-\frac{f_{t}}{1+\alpha}\right) / \lambda_{u}}{D}
$$

where $\beta^{v}=1 / \sigma_{v}^{2}, \beta^{s}=1 /\left(\lambda_{b} / \lambda_{u}\right)^{2} \sigma_{b}^{2}$ and $D=1 / \operatorname{var}\left(u_{t}\right)=\beta^{v}+\beta^{u}+\beta^{s}$. For the exchange rate signal, the precision is complex and depends both on $\sigma_{b}^{2}$ and $\lambda_{b} / \lambda_{u}$, the latter being endogenous. By substituting (23) into (16) and using the fact that $\int_{0}^{1} v_{t}^{i} d i=u_{t}$ in computing $\bar{E}_{t} u_{t}$, it can be easily seen that (21) indeed holds. 


\section{III.A.3 The Magnification Factor}

Since investors do not know whether a change in the exchange rate is driven by non-fundamentals shocks or fundamentals information of other investors, they always revise their expectations of fundamentals when the exchange rate changes (equation (23)). This magnifies the impact of non-fundamental shocks on the exchange rate. More specifically, from (16) and (23), we can see that a change in $b_{t}$ has two effects on $s_{t}$. First, it affects $s_{t}$ directly in (16) through the risk-premium channel. Second, this direct effect is magnified by an increase in $\bar{E}_{t} u_{t}$ from (23). The degree of magnification is given by $z>1$ :

$$
\lambda_{b}=z \lambda_{b}^{c}
$$

where $\lambda_{b}^{c}$ is defined in (20). ${ }^{22}$ The magnification factor can be written as

$$
z=1+x^{2} \frac{\sigma_{v}^{2}}{\sigma_{b}^{2}}
$$

where $x=\lambda_{u} / \lambda_{b}$ is the relative weight of $u_{t}$ and $b_{t}$ in the exchange rate equation.

Figure 1 shows the impact of some key parameters on magnification. A rise in the private signal variance $\sigma_{v}^{2}$ at first raises magnification and then lowers it (Panel A). Two opposite forces are at work. First, as shown in (25), for a given $x$ an increase in $\sigma_{v}^{2}$ raises magnification. This is because more weight is given to the exchange rate as a source of information. Second, a rise in $\sigma_{v}^{2}$ implies less information and therefore a lower relative weight $x$ of fundamentals in the exchange rate equation (Panel B). This makes the exchange rate less informative about fundamentals and reduces the magnification factor. On the other hand, a rise in the variance $\sigma_{b}^{2}$ of non-fundamentals shocks always reduces magnification since it makes it more difficult to extract information about fundamentals from

\footnotetext{
${ }^{22}$ We implicitly assume that the conditional variance of the exchange rate is the same in the two models. Holding constant the precision of the private signal, one can always change the precision of the signal with common knowledge to make sure that this is the case. In section IV we show that at the quantitative level the main results are not much different when we instead hold the precision of the signals the same in the two models. In that case the conditional variance can be higher in either model. On the one hand, the exchange rate provides an additional piece of information in the heterogeneous information model, which lowers the conditional variance. On the other hand, the magnification factor $z$ raises the conditional variance.
} 
the exchange rate. ${ }^{23}$ Numerical simulations also show that a rise in the variance $\sigma_{u}^{2}$ reduces the magnification factor. Intuitively, a higher variance of fundamentals shocks raises the risk-premium and therefore increases the relative weight of nonfundamentals shocks. This reduces the information content of the exchange rate.

\section{III.B Higher Order Expectations: Further Magnification}

As discussed in section II, higher order expectations differ from simple average expectations when expectations of future fundamentals at time $t$ are affected by private signals from previous periods. In the context of a model that satisfies this property, Allen, Morris and Shin [2002] show that higher order expectations of a future fundamental are more sensitive to public information than the average expectation: in forming expectations of other investors' expectations more weight is given to public information that is available to all investors. Since in our setup the exchange rate is an important public signal, it has a larger impact on higher order expectations, leading to additional magnification. ${ }^{24}$

In our model, expectations of future fundamentals are affected by private signals from previous periods as long as $T>1$. Consider the case where $T=2$, while we still keep $\rho_{1}=\rho_{2}=\rho_{b}=0$. The exchange rate equation (7) becomes:

$$
s_{t}=\frac{1}{1+\alpha}\left[f_{t}+\frac{\alpha}{1+\alpha} \bar{E}_{t} u_{t-1}+\left(\frac{\alpha}{1+\alpha}\right)^{2} \bar{E}_{t}^{2} u_{t}+\ldots\right]-\frac{\alpha}{1+\alpha} \gamma \sigma_{t}^{2} b_{t}
$$

where the number of terms in square brackets goes to infinity. Thus, we have infinite regress. In order to see the role of higher order expectations, consider $\bar{E}_{t}^{2} u_{t}=\bar{E}_{t}\left(\bar{E}_{t+1} u_{t}\right)$. Appendix $\mathrm{C}$ shows that:

$$
\bar{E}_{t}^{2} u_{t}=\bar{E}_{t} u_{t}+k_{u}\left(\bar{E}_{t} u_{t}-u_{t}\right)
$$

where $k_{u}=\partial E_{t+1}^{i} u_{t} / \partial v_{t}^{i}>0$ is the impact of the private signal at time $t$ on an investor's expectation at time $t+1$. Since $\bar{E}_{t} u_{t}$ depends positively on $s_{t}$ in a way analogous to (23), higher order expectations give more weight to the exchange rate than simple average expectations, contributing to the magnification effect. Appendix $\mathrm{C}$ shows that as the order of expectation increases further, even more weight is given to the exchange rate.

${ }^{23}$ This can be seen directly from (25). It is only partially offset by the resulting rise in $x$.

${ }^{24}$ Allen, Morris and Shin [2002] focus on the case of infinite noise, so that the asset price itself is not a signal. 


\section{III.C Persistence}

An additional feature of the model is the endogenous persistence of the impact of non-fundamental shocks on the exchange rate. This is caused by the combination of heterogeneous information and giving positive weight to information from previous periods in forming expectations (for $T>1$ ). To illustrate persistence, consider the case presented above where $T=2$. Persistence comes from the fact that $E_{t}^{i} u_{t-1}$ depends on prior information about $u_{t-1}$ at $t-1$. One source of prior information is the exchange rate at $t-1$. Since the exchange rate at $t-1$ is affected by $b_{t-1}$ a non-fundamental shock at $t-1$ continues to affect the exchange rate at time $t$ by affecting the expectation at time $t$ of the future fundamental $u_{t-1}=f_{t+1}$. This is the case even if the non-fundamental shock itself has no persistence $\left(\rho_{b}=0\right)$, as we have assumed so far. ${ }^{25}$ In the common knowledge model, a $b$-shock has no persistent impact on the exchange rate if the shock itself has no persistence.

From (15) it is immediately clear that an entirely transitory $b$-shock continues to impact the exchange rate for $T$ periods. After $T$ periods there is no longer any uncertainty about whether a change in the exchange rate $T$ periods earlier was caused by non-fundamentals or fundamentals. The reason is that the vector $\mathbf{u}_{\mathbf{t}}$ is known at $t+T$. From (15) investors then also know $b_{t}$ at time $t+T$. The impact of a $b$-shock dies down over time as investors gradually learn more about the fundamentals.

The persistence of the $b$-shock on the exchange rate is also affected by the persistence of the shock itself. In the common knowledge model, the persistence of the impact of a $b$-shock on the exchange rate is the same as the persistence of the shock itself. In the heterogeneous information model, persistence is largely driven by the persistence of the magnification factor. More precisely, it is driven by the persistence of the impact of the $b$-shock on expected future fundamentals and therefore the persistence of the rational confusion. When the $b$-shock itself becomes more persistent, it becomes more difficult for investors to learn from exchange rates subsequent to time $t$ whether a change in the exchange rate at time $t$ was a result of fundamentals or non-fundamentals $\left(b_{t}\right)$. The rational confusion is

\footnotetext{
${ }^{25}$ This result is related to findings by Brown and Jennings [1989] and Grundy and McNichols [1989], who show in the context of two-period noisy rational expectations models that the asset price in the second period is affected by the asset price in the first period.
} 
therefore more persistent and so is the impact of $b$-shocks on the exchange rate. ${ }^{26}$

\section{The General Dynamic Model}

In this section we fully solve the general dynamic structure of the model where $T>1$ and both fundamentals and non-fundamentals follow an autoregressive process. We first illustrate the key implications of the model with a benchmark parameterization. Then we consider how the main features are affected by the model's parameters, which provides further insight into the operation of the model. Finally, in the last subsection we discuss the 'excess volatility' puzzle and solve a stickyprice version of the model. We illustrate how information dispersion contributes to excess volatility.

\section{IV.A A Benchmark Case}

The parameters of the benchmark case are reported in Table 1 . They are chosen mainly to illustrate the potential impact of information dispersion; they are not calibrated or chosen to match any data moments. We assume that $u$, and therefore the fundamental, follows a random walk $(\rho=0)$. We assume that the extent of private information is small by setting a high standard deviation of the private signal error of 0.08 , versus a 0.01 standard deviation of $u$. Although we have made assumptions about both $\sigma_{b}$ and risk-aversion $\gamma$, they enter multiplicatively in the model, so only their product matters. We allow for an AR coefficient of 0.8 of the non-fundamentals $b$-shock. Finally, we assume that $T=8$, so that agents obtain private signals about fundamentals eight periods later.

Figure 2 shows some of the key results from the benchmark parameterization. Panels $\mathrm{A}$ and $\mathrm{B}$ show the dynamic impact on the exchange rate in response to one-standard deviation shocks in the private and common knowledge models. In both models the non-fundamentals shocks are the $b$-shocks. In the heterogeneous

\footnotetext{
${ }^{26}$ When $b_{t}$ follows a random walk, the persistence of its impact on the exchange rate is smaller in the heterogeneous information model than in the common knowledge model because the rational confusion in the heterogeneous information model is temporary (lasts $T$ periods). However, persistence in the common knowledge model has little meaning when the impact of $b$-shocks on the exchange rate is very small.
} 
information model the fundamentals shocks are the $u$-shocks. In the common knowledge model the fundamentals shocks are both $u$-shocks and $\varepsilon^{v}$ shocks, which affect the exchange rate through the publicly observable fundamentals $f$ and $v$. In order to facilitate comparison, we again set the precision of the public signal such that the conditional variance of next period's exchange rate is the same as in the heterogeneous information model. This implies that the $b$-shocks have the same risk-premium effect in the two models. We will show below that our key results do not depend on the assumed precision of the public signal.

\section{Magnification}

The magnification factor in the benchmark parameterization turns out to be substantial: 7.2. This is visualized in Figure 2 by comparing the instantaneous response of the exchange rate to the $b$-shocks in the two models in panels $\mathrm{A}$ and B. The only reason the impact of a $b$-shock is so much bigger in the heterogeneous information model is the magnification factor associated with information dispersion.

We saw in section III that higher order expectations contribute to the magnification factor. It is hard to quantify the role of higher order expectations since one cannot remove them. Nonetheless we can get a sense of the importance of higher order expectations by doing an artificial experiment: we replace the higher order expectations of future $f$ 's and $b$ 's in the exchange rate equation (7) with simple average expectations. Both with and without higher order expectations the coefficient on $b_{t}$ on the right hand side of (7) is $\bar{\lambda}_{b}=-\alpha \gamma \sigma^{2} /(1+\alpha)$. The question is how the right-hand side of (7), i.e., the expected present discounted value of future fundamentals and $b$ 's, depends on $s_{t}$. Let this impact be $\nu$. Then, the coefficient on $b_{t}$ in the equilibrium exchange rate equation (15) is $\lambda_{b}=\bar{\lambda}_{b} /(1-\nu)$. For higher order expectations $\nu=0.962$, while for average expectations $\nu=0.907 .{ }^{27}$ This implies that $1 /(1-\nu)$ is 2.4 larger under higher order expectations, implying also a magnification factor that is 2.4 larger. This suggests a substantial role for higher

\footnotetext{
${ }^{27}$ For higher order expectations $\nu$ follows immediately since we know $\lambda_{b}$ from the solution method.
} 
order expectations in contributing to the magnification factor.

\section{Persistence}

We can see from panel A that after the initial shock the impact of the $b$-shocks dies down almost as a linear function of time. The half-life of the impact of the shock is 3 periods. After 8 periods the rational confusion is resolved and the impact is the same as in the public information model, which is close to zero. The meaning of a 3-period half-life depends of course on what we mean by a period in the model. As we will discuss below, what matters in the model is not so much the length of a period, but the length of time it takes for uncertainty about future fundamentals to be resolved.

\section{Exchange rate disconnect in the short and the long run}

Panel C reports the contribution of non-fundamentals trade to the variance of $s_{t+k}-s_{t}$ at different horizons. In the heterogeneous information model, $70 \%$ of the variance of a 1-period change in the exchange rate is driven by non-fundamentals shocks, while in the common knowledge model it is a negligible $1.3 \%$. This is almost entirely due to the much larger impact of non-fundamentals shocks in the heterogeneous information model.

The low contribution of non-fundamentals trade to exchange rate volatility in the common knowledge model does not depend on the extent of noise in the public signal. In our simulations, we set the standard deviation of the public signal noise at 0.033 , so that the unconditional variance of the 1-period change in the exchange rate is the same as in the heterogeneous information model. When we set the standard deviation of the public noise at 0 and 0.08 (same as private signal), the contribution of non-fundamentals shocks to the variance of the 1-period change in the exchange rate is respectively $0.6 \%$ and $2.4 \%$.

While in the short-run non-fundamentals shocks dominate in the heterogeneous information model, in the long-run fundamentals shocks dominate. The impact of a change in non-fundamentals trade on the exchange rate gradually dies down as investors learn more about the fundamentals and rational confusion dissipates. On the other hand, the impact of $u$-shocks on the exchange rate rises over time as we get closer to the time of the rise in the fundamental $f$ and as agents gradually learn that the shock took place. In panel $\mathrm{C}$ we see that the contribution of non- 
fundamentals shocks to the variance of $s_{t+k}-s_{t}$ declines as the horizons $k$ increases. For a three-period horizon the contribution of the two shocks to exchange rate volatility is about the same, while the contribution of $b$-shocks declines to less than $20 \%$ after ten periods.

In order to determine the relationship between exchange rates and fundamentals, panel $\mathrm{D}$ reports the $R^{2}$ of a regression of $s_{t+k}-s_{t}$ on all current and lagged observable fundamentals. In the heterogeneous information model this includes all one period changes in the fundamental $f_{t}$, from $t+k-1$ to $t+k$ and back. In the common knowledge model it also includes the corresponding one-period changes in the public signal $v$. The $R^{2}$ is close to 1 for all horizons in the common knowledge model, while it is much lower in the heterogeneous information model. ${ }^{28}$ At the one-period horizon it is only 0.14 , and then rises as the horizon increases, to 0.8 for a 20-period horizon. This is consistent with extensive findings that macroeconomic fundamentals have weak explanatory power for exchange rates in the short to medium run, starting with Meese and Rogoff [1983], and findings of a much closer relationship over longer horizons. ${ }^{29}$ Two factors account for the results in panel D. The first is that the relative contribution of non-fundamentals shocks to exchange rate volatility is large in the short-run and small in the long-run, as illustrated in panel $\mathrm{C}$. The second factor is that through private signals the exchange rate is also affected by future fundamentals that are not yet observable today. This second factor again affects the exchange rate more in the short-run than the long-run.

\section{Exchange rate and future fundamentals}

Recently Engel and West [2002] and Froot and Ramadorai [2002] have reported evidence that exchange rate changes predict future fundamentals, but only weakly so. Our model is consistent with these findings. Panel $\mathrm{E}$ of Figure 2 reports the $R^{2}$ of a regression $f_{t+k}-f_{t+1}$ on $s_{t+1}-s_{t}$ for $k \geq 2$. The $R^{2}$ is positive, but is never above 0.14 . The exchange rate is affected by the private signals of future fundamentals, which aggregate to $u$. However, most of the short-run volatility of

\footnotetext{
${ }^{28}$ The high $R^{2}$ in the common knowledge model is again independent of the extent of noise in the public signal.

${ }^{29}$ See MacDonald and Taylor [1993], Mark [1995], Chinn and Meese [1995], Mark and Sul [2001] and Froot and Ramadorai [2002].
} 
exchange rates is associated with non-fundamentals shocks, which do not predict future fundamentals. Even though exchange rates have only weak explanatory power for future fundamentals, investors in the model still give a lot of weight to the exchange rate as a source of information because the private signals are even weaker.

\section{IV.B Sensitivity to Model Parameters}

In order to gain further insight, we now examine how the main results are affected by parameter values. Figure 3 contains seven panels showing (i) the magnification factor, (ii) the contribution of $b$-shocks to $\operatorname{var}\left(s_{t+1}-s_{t}\right)$, and (iii) persistence, measured by the half-life of the impact of $b$-shocks on the exchange rate. They are each plotted as a function of a specific parameter.

\section{Private information}

Perhaps the most important parameter of the model is the precision of the private signal. Panel A shows the sensitivity to $\sigma_{v}$, the standard deviation of the error in the private signal. In section III we already discussed the impact of $\sigma_{v}$ on magnification, $z_{t}$. Even though the current model is much richer, the results in this respect are qualitatively the same as before. In particular, magnification rises up to $\sigma_{v}=0.06$, and then drops. Consistent with that we also find that the contribution of non-fundamentals shocks to exchange rate volatility first rises, up to $\sigma_{v}=0.08$, and then drops.

The overall implication from these results is that the impact of information dispersion on exchange rate dynamics is most powerful for some intermediate range. When $\sigma_{v}^{2}$ is low it is possible to raise the magnification factor, increase the contribution of non-fundamentals shocks to exchange rate volatility, while at the same time making the impact of non-fundamentals shocks more persistent. When infor-

mation becomes too disperse, however, the magnification factor decreases and the contribution of non-fundamentals shocks to exchange rate volatility is lower.

\section{Non-fundamental shocks}

Panel B illustrates the role of the standard deviation $\sigma_{b}$ of non-fundamentals trade, and panel $\mathrm{C}$ the role of persistence $\rho_{b}$ of the non-fundamentals shocks. Both 
a higher standard deviation and more persistence of the non-fundamentals shocks reduce magnification as the exchange rate becomes less informative about fundamentals. In both cases the contribution of non-fundamentals shocks to exchange rate volatility is almost constant over a wide range of parameters. One can for example significantly reduce the standard deviation of non-fundamentals shocks, while the contribution of these shocks to exchange rate volatility remains almost the same. This is a result of two factors. First, the magnification factor rises. Second, less weight is given to private signals when the exchange rate signal becomes stronger, weakening the contribution of $u$-shocks to exchange rate volatility. When $\sigma_{b} \rightarrow 0$ the magnification factor converges to infinity, but the contribution of nonfundamentals shocks to exchange rate volatility nonetheless goes to zero. That is a desirable property since it would be peculiar if infinitesimally small idiosyncratic trades become the dominant source of exchange rate volatility.

As anticipated in the previous section, we also see from panel $\mathrm{C}$ that a rise in persistence of $b$-shocks leads to more persistence of its impact on the exchange rate. It takes more time for investors to distinguish between fundamentals and non-fundamentals shocks, so that the rational confusion persists longer.

It is important to stress that the closer relationship between exchange rates and fundamentals in the long-run than the short run is entirely the result of the fact that the rational confusion dissipates in the long run; it is not due to our assumption that non-fundamentals trade is stationary, while the fundamental is non-stationary. Consider for example the case where $\rho_{b}=1$ and $\sigma_{b}=0.006$ and other parameters remain unchanged. Both fundamentals and non-fundamentals trade are then nonstationary. In this case, the long-run impact of non-fundamentals trade is the same in the public and heterogeneous information models and is only associated with the risk-premium channel. However, the short-run impact is much larger in the heterogeneous information model due to the magnification factor (which is 4.1 in this case), while in the common knowledge model the short and long-run impact 
are the same. ${ }^{30}$

\section{Fundamental shocks}

Panels D and E of Figure 3 show the impact of respectively the standard deviation and persistence of fundamentals shocks. An increase in either $\sigma_{u}$ or $\rho$ reduces the magnification factor. The increased risk raises the risk-premium and therefore the coefficient of $b_{t}$ in the exchange rate. This makes it more difficult to extract information about fundamentals from the exchange rate. The contribution of nonfundamentals shocks to exchange rate volatility is again remarkably insensitive to parameters. Even though more volatile fundamentals now generate more exchange rate volatility, the same is the case for non-fundamentals shocks as a result of the rise in the risk-premium.

\section{The parameter $T$}

Panel $\mathrm{F}$ shows the impact of $T$. Magnification rises as agents have private information about fundamentals further into the future ( $T$ bigger). The higher $T$, the more information agents have at any point in time, and therefore the lower the uncertainty about next period's exchange rate. This reduces the risk-premium and therefore the coefficient of $b_{t}$ in the exchange rate, so that the exchange rate becomes more informative about fundamentals and the magnification factor rises. Persistence also increases as $T$ goes up as it takes $T$ periods for investors to learn the actual size of the $b$-shock and for rational confusion to dissipate.

The size of the parameter $T$ also brings up the question of what we mean by a "period" in the model. This is particularly relevant in the context of persistence. It turns out that what is critical in the model is not the length of a period, but the length of time it takes for uncertainty about future macro variables to be resolved. For example, assume that $T$ is eight months. If a period in our model is a month, then $T=8$. If a period is three days, then $T=80$. When we change the length of a period we also need to change other model parameters, such as the standard deviations of the shocks. We find that the half-life of the impact of

\footnotetext{
${ }^{30}$ In this case, the relative contribution of non-fundamentals trade to exchange rate volatility is $76 \%$ for a 1 -period horizon and $19 \%$ for a 20 -period horizon. Similarly, the $R^{2}$ of a regression of the change in the exchange rate on current and lagged observable fundamentals rises from 0.2 for a 1-period horizon to 0.75 for a 20 -period horizon.
} 
non-fundamentals shocks on the exchange rate that can be generated by the model remains virtually unchanged as we change the length of a period. ${ }^{31}$ For $T=8$ the model can generate a half-life of about 3, as in the benchmark parameterization. When $T=80$, we can obtain a half-life of about 30 when we change other model parameters. $^{32}$ In both cases the half-life is 3 months. Persistence is therefore driven critically by the length of time it takes for uncertainty to resolve itself. Deviations from fundamentals can be very long lasting when expectations about future fundamentals take a long time to verify, such as expectations about the long-term technology growth rate of the economy.

\section{IV.C 'Excess' Volatility}

Although our focus has been on the exchange rate determination puzzle, we briefly discuss the puzzle of excess volatility of exchange rates relative to fundamentals. The exchange rate determination puzzle and the excess volatility puzzle are two distinct puzzles that may not have the same explanation. For example, the Dornbusch-overshooting model can easily generate excess volatility, but exchange rates are driven entirely by fundamentals. In our model the opposite is true under the benchmark parameterization. The model generates a weak relationship between exchange rates and fundamentals, but the standard deviation of a one-period change in the exchange rate is only 0.7 times the standard deviation of a one-period change in the fundamentals. This does not mean that information dispersion plays no role in understanding the excess volatility puzzle. We will show that information dispersion significantly contributes to excess volatility, but other factors play a role as well. In particular, we will introduce nominal rigidities and increase the persistence of the fundamental.

In order to shed light on the excess volatility puzzle, consider one-period excess volatility measured by the ratio of the variances of exchange rate and fundamentals

\footnotetext{
${ }^{31}$ In doing so we restrict parameters such that (i) the contribution of $b$-shocks to $\operatorname{var}\left(s_{t+1}-s_{t}\right)$ is held at around $70 \%$ and (ii) the impact of $b$-shocks on exchange rate volatility remains largely driven by information dispersion (large magnification factor).

${ }^{32}$ For example, when we change the benchmark parameterization such that $T=80, \sigma_{v}=0.26$, $\sigma_{u}=0.0016$ and $\alpha=44$, the half-life is 28 periods. The magnification factor is 48 and the contribution of non-fundamentals trade to 1-period changes in the exchange rate is $69 \%$.
} 
changes. It is useful to write this ratio as follows:

$$
\frac{\operatorname{var}\left(s_{t+1}-s_{t}\right)}{\operatorname{var}\left(f_{t+1}-f_{t}\right)}=\frac{1}{1-\operatorname{contr}} \frac{\operatorname{var}^{u}\left(s_{t+1}-s_{t}\right)}{\operatorname{var}\left(f_{t+1}-f_{t}\right)}
$$

where contr is the fraction of the unconditional variance of one-period exchange rate changes contributed by non-fundamentals trade and $\operatorname{var}^{u}\left(s_{t+1}-s_{t}\right)$ is the variance of one-period exchange rate changes resulting from fundamentals shocks. The excess volatility ratio is made of two elements. The first element depends on the contribution of non-fundamentals trade to exchange rate volatility. We have seen that information dispersion significantly raises contr, for example to 0.7 under the benchmark parameterization. This raises excess volatility ratio by a factor larger than 3. So information dispersion raises the first element. The second element depends on how much shocks to fundamentals themselves contribute to the ratio of exchange rate to fundamentals variance. In the benchmark parameterization this second element is very low: 0.15. Even though the fundamental follows a random walk, this ratio is less than 1 in the benchmark parameterization both because a change in $u_{t}$ affects the fundamental in the future and because investors only have incomplete information about the change in $u_{t}$.

In order to obtain substantial excess volatility, we need to raise the second term on the right hand side of (28). For this purpose, we introduce two changes in the benchmark model. First, we raise $\rho$. This implies that a rise in the fundamental today is expected to lead to a much larger long-run increase in the fundamental, so that the exchange rate changes much more than an unexpected increase in the fundamental. Second, we introduce nominal rigidities, as in the Dornbuschovershooting model. We illustrate the impact of nominal rigidities by assuming that prices gradually adjust with delay to restore purchasing power parity according to:

$$
p_{t+1}^{*}-p_{t}^{*}=\phi\left(p_{t}-s_{t}-p_{t}^{*}\right)
$$

where $\phi$ is a parameter between 0 and 1 , with a lower number implying more rigid prices. ${ }^{33}$

Consider the impact of raising $\rho$ from 0 to 0.8 and introducing nominal rigidities with $\phi=0.1$. We also reduce the standard deviation of non-fundamentals

\footnotetext{
${ }^{33}$ When $\phi=1$, prices adjust with only one period delay to restore purchasing power parity. This is still slower than in the baseline model, where prices adjust instantaneously.
} 
trade from 0.01 to $0.003 .{ }^{34}$ Under this parameterization the contribution of nonfundamentals trade to exchange rate volatility is $82 \%($ contr $=0.82)$ and it is still mostly the result of information dispersion as the magnification factor remains high at 3.4. Fundamentals shocks alone lead to a variance of the exchange rate that is 1.7 times the variance of fundamentals (the second element in (28)). The large contribution of non-fundamentals shocks makes the overall variance of the 1 -period change in the exchange rate 9.4 times the variance of 1-period changes in fundamentals. This example shows that information dispersion exacerbates excess volatility.

\section{Conclusion}

The large volume of trade in the foreign exchange market and the close relationship between order flow and exchange rates suggests that investor heterogeneity may be a key element in understanding exchange rate behavior. In this paper, we have explored the implications of information dispersion in a simple model of exchange rate determination. We have shown that these implications are rich and that investors' heterogeneity could be an important element in explaining the behavior of exchange rates. In particular, the model can account for some important stylized facts on the relationship between exchange rates and fundamentals: (i) fundamentals have little explanatory power for short to medium run exchange rate movements, (ii) over longer horizons the exchange rate is primarily driven by fundamentals, (iii) exchange rate changes are a weak predictor of future fundamentals. We have also shown that information dispersion contributes to excess volatility of the exchange rate relative to fundamentals, although other factors play a role as well.

The paper should be considered only as a first step in a promising line of research. A natural next step is to introduce microstructure institutions such as foreign exchange dealers to the model. This will help to better integrate microstruc-

\footnotetext{
${ }^{34}$ The increased exchange rate volatility that results from nominal rigidities and raising $\rho$ reduces the magnification factor. We therefore reduce the standard deviation of non-fundamentals shocks in order to keep the magnification factor high. The contribution of non-fundamentals shocks then remains primarily driven by the rational confusion resulting from information dispersion.
} 
ture and macro models of exchange rate determination. Moreover, it should enable us to bring the model to the data. Modeling microstructure institutions allows us to compute order flow in the model, which is closely related to non-fundamentals shocks. This may give us an estimate on the size of these shocks and determine the extent of magnification that is necessary to understand observed exchange rate volatility. The magnification factor may be large. Back-of-the-envelope calculations by Gennotte and Leland [1990] in the context of a static model for the U.S. stock market crash of October 1987 suggest that the impact of a $\$ 6$ bln. nonfundamental shock was magnified by a factor 250 due to rational confusion about the source of the stock price decline.

There are two other natural directions in which the model can be extended. The first is to explicitly model nominal rigidities as in the "new open economy macro" literature. In that literature exchange rates are entirely driven by fundamentals. Conclusions that have been drawn about optimal monetary and exchange rate policies are likely to be substantially revised when introducing investor heterogeneity. Another direction is to consider alternative information structures. For example, the information received by agents may differ in its quality or in its timing. There can also be heterogeneity about the knowledge of the underlying model $^{35}$ The rapidly growing body of empirical work on order flows in the microstructure literature is likely to increase our understanding of the nature of the information structure, providing guidance to future modeling.

${ }^{35}$ See Honkapohja and Mitra (2002) for a recent analysis in different contexts. 


\section{Appendix}

\section{A Derivation of equation (7)}

It follows from (1), (2), (3), and (6) that

$$
s_{t}=\frac{\alpha}{1+\alpha} \bar{E}_{t}^{1}\left(s_{t+1}\right)+\frac{1}{1+\alpha} f_{t}-\frac{\alpha}{1+\alpha} \gamma \sigma_{t} b_{t}
$$

Therefore

$$
\bar{E}_{t}^{1}\left(s_{t+1}\right)=\frac{\alpha}{1+\alpha} \bar{E}_{t}^{2}\left(s_{t+2}\right)+\frac{1}{1+\alpha} \bar{E}_{t}^{1}\left(f_{t+1}\right)-\frac{\alpha}{1+\alpha} \gamma \sigma_{t+1} \bar{E}_{t}^{1}\left(b_{t+1}\right)
$$

Substitution into (30) yields

$$
s_{t}=\left(\frac{\alpha}{1+\alpha}\right)^{2} \bar{E}_{t}^{2}\left(s_{t+2}\right)+\frac{1}{1+\alpha} \sum_{k=0}^{1}\left(\frac{\alpha}{1+\alpha}\right)^{k} \bar{E}_{t}^{k}\left(f_{t+k}-\alpha \gamma \sigma_{t+k} b_{t+k}\right)
$$

Continuing to solve for $s_{t}$ this way by forward induction yields (7).

\section{B Conditional variance of next period's exchange rate}

Consider the case of common knowledge. From (18) at $t+1$ :

$$
\sigma_{t}^{2}=a+b \sigma_{t+1}^{4}
$$

where $a=\left(1+d \tilde{\alpha} \beta^{v, c} / \beta^{u}\right) / d(1+\alpha)^{2}, b=\gamma^{2} \sigma_{b}^{2} \widetilde{\alpha}$ and $\widetilde{\alpha}=(\alpha /(1+\alpha))^{2}$. In the steady state, $\sigma^{2}=\sigma_{t}^{2}=\sigma_{t+1}^{2}$. It is easy to see that:

$$
\sigma^{2}=\frac{1 \pm \sqrt{1-4 a b}}{2 b}
$$

Thus, as long as $4 a b<1$, there are two steady states with low and high $\sigma^{2}$. From (33), $d \sigma_{t}^{2} / d \sigma_{t+1}^{2}=2 b \sigma^{2}=1 \pm \sqrt{1-4 a b}$. Thus, $d \sigma_{t}^{2} / d \sigma_{t+1}^{2}<1$ around the low $\sigma^{2}$ steady state and $d \sigma_{t}^{2} / d \sigma_{t+1}^{2}>1$ for the high $\sigma^{2}$ steady state. Since $\sigma_{t}^{2}$ is a forwardlooking variable, only the low $\sigma^{2}$ steady state gives a stable equilibrium. ${ }^{36}$ The

${ }^{36}$ See, for example, Blanchard and Fischer [1989], ch. 5 for a discussion of these issues. 
high steady state equilibrium is knife-edge, in that it can only be an equilibrium today if one believes that $\sigma_{t}$ is exactly the high steady state equilibrium at all future dates. In the model with heterogeneous information, the results are similar, even though $\sigma^{2}$ has to be evaluated numerically.

\section{Higher order expectations}

In this Appendix we derive a lemma determining the bias of higher order expectations that is used to derive Equation (27). Consider a stochastic variable $x_{t+1}$ in the model with $T>1$. To estimate its value at time $t+1$, assume that an investor uses a linear rule based on all relevant available information:

$$
E_{t+1}^{i} x_{t+1}=k_{s} \mathbf{s}_{t}+k_{s}^{1} s_{t+1}+k_{f} \mathbf{f}_{t}+k_{f}^{1} f_{t+1}+k_{u} \mathbf{v}_{t}^{i}+k_{u}^{1} v_{t+1}^{i}
$$

Only private signals in the last $T$ periods matter, such that $\mathbf{v}_{t}^{i \prime}=\left(v_{t}^{i}, v_{t-1}^{i}, \ldots, v_{t-T+2}^{i}\right)$.

Lemma 1: When investors use the rule (35) we have:

$$
\bar{E}_{t}\left(\bar{E}_{t+1} x_{t+1}\right)-\bar{E}_{t} x_{t+1}=k_{u}\left(\bar{E}_{t} \mathbf{u}_{t}-\mathbf{u}_{t}\right)
$$

Proof: First compute $\bar{E}_{t} x_{t+1}$. From (35) we find:

$$
E_{t}^{i} x_{t+1}=E_{t}^{i}\left(E_{t+1}^{i} x_{t+1}\right)=k_{s} \mathbf{s}_{t}+k_{f} \mathbf{f}_{t}+k_{u} \mathbf{v}_{t}^{i}+k_{s}^{1} E_{t}^{i} s_{t+1}+k_{f}^{1} E_{t}^{i} f_{t+1}+k_{u}^{1} E_{t}^{i} v_{t+1}^{i}
$$

Aggregating:

$$
\bar{E}_{t} x_{t+1}=k_{s} \mathbf{s}_{t}+k_{f} \mathbf{f}_{t}+k_{u} \mathbf{u}_{t}+k_{s}^{1} \bar{E}_{t} s_{t+1}+k_{f}^{1} \bar{E}_{t} u_{t+1-T}+k_{u}^{1} \bar{E}_{t} u_{t+1}
$$

Now compute $\bar{E}_{t}\left(\bar{E}_{t+1} x_{t+1}\right)$. Aggregating (35) we have:

$$
\bar{E}_{t+1} x_{t+1}=k_{s} \mathbf{s}_{t}+k_{f} \mathbf{f}_{t}+k_{u} \mathbf{u}_{t}+k_{s}^{1} s_{t+1}+k_{f}^{1} f_{t+1}+k_{u}^{1} u_{t+1}
$$

Then:

$$
\bar{E}_{t}\left(\bar{E}_{t+1} x_{t+1}\right)=k_{s} \mathbf{s}_{t}+k_{f} \mathbf{f}_{t}+k_{u} \bar{E}_{t} \mathbf{u}_{t}+k_{s}^{1} \bar{E}_{t} s_{t+1}+k_{f}^{1} \bar{E}_{t} u_{t+1-T}+k_{u}^{1} \bar{E}_{t} u_{t+1}
$$

Subtracting (38) from (40) gives (36). Q.E.D. 
Since $\bar{E}_{t} \mathbf{u}_{t}$ depends positively on $s_{t}$, second order order expectations give more weight to the exchange rate than simple average expectations. It is easy to see that third order expectations give more weight to the exchange rate than second order expectations, and so on. For third order expectations, using (36) one period ahead, we have:

$$
\bar{E}_{t}^{3} x_{t+2}=\bar{E}_{t}^{2} x_{t+2}+k_{u}\left(\bar{E}_{t} \bar{E}_{t+1} \mathbf{u}_{t+1}-\bar{E}_{t} \mathbf{u}_{t+1}\right)
$$

where from Lemma 1

$$
\bar{E}_{t}\left(\bar{E}_{t+1} \mathbf{u}_{t+1}\right)-\bar{E}_{t} \mathbf{u}_{t+1}=k_{u, 1}\left(\bar{E}_{t} \mathbf{u}_{t}-\mathbf{u}_{t}\right)
$$

Here $k_{u, 1}$ is a matrix with the coefficients on $\mathbf{v}_{t}^{i}$ of $E_{t+1}^{i} \mathbf{u}_{t+1}$.

\section{Solution method with two-period overlapping investors}

This method is related to Townsend (1983, section VIII). We start with the conjectured equation (12) for $s_{t}$ and check whether it is consistent with the model, in particular with equation (6). For this, we need to estimate the conditional moments of $s_{t+1}$ and express them as a function of the model's innovations. Finally we equate the parameters from the resulting equation to the initially conjectured equation.

\section{D.1 The exchange rate equation}

From (2), (1), and the definition of $f_{t}$, it is easy to see that $i_{t}^{*}-i_{t}=\left(f_{t}-s_{t}\right) / \alpha$. Thus, (6) gives (for a constant $\sigma_{t}^{2}$ ):

$$
s_{t}=\frac{\alpha}{1+\alpha} \bar{E}\left(s_{t+1}\right)+\frac{f_{t}}{1+\alpha}-\frac{\alpha}{1+\alpha} \gamma b_{t} \sigma^{2}
$$

We want to express (43) in terms of current and past innovations. First, we have $f_{t}=D(L) \varepsilon_{t-T}^{u}$, where $D(L)=d_{1}+d_{2} L+d_{3} L+\ldots$ is given by (11) and the definition of $u_{t}$, with $d_{s}=\left(1-\rho^{s}\right) /(1-\rho)$. Second, using (5) we can write $b_{t}=C(L) \varepsilon_{t}^{b}$, where $C(L)=1+\rho_{b} L+\rho_{b}^{2} L^{2}+\ldots$. What remains to be computed are $\bar{E}\left(s_{t+1}\right)$ and $\sigma^{2}$. 
Applying (12) to $s_{t+1}$, decomposing $A(L)$ and $B(L)$, we have

$$
s_{t+1}=a_{1} \varepsilon_{t+1}^{u}+b_{1} \varepsilon_{t+1}^{b}+\theta^{\prime} \xi_{t}+A^{*}(L) \varepsilon_{t-T}^{u}+B^{*}(L) \varepsilon_{t-T}^{b}
$$

where $\xi_{t}^{\prime}=\left(\varepsilon_{t}^{u}, \ldots, \varepsilon_{t-T+1}^{u}, \varepsilon_{t}^{b}, \ldots, \varepsilon_{t-T+1}^{b}\right)$ represents the vector of unobservable innovations, $\theta^{\prime}=\left(a_{2}, a_{3}, \ldots, a_{T+1}, b_{2}, \ldots, b_{T+1}\right)$ and $A^{*}(L)=a_{T+2}+a_{T+3} L+\ldots$ (with a similar definition for $B^{*}(L)$ ). Thus, we have (since $\varepsilon_{j}^{u}$ and $\varepsilon_{j}^{b}$ are known for $j \leq t-T)$ :

$$
\begin{gathered}
E_{t}^{i}\left(s_{t+1}\right)=\theta^{\prime} E_{t}^{i}\left(\xi_{t}\right)+A^{*}(L) \varepsilon_{t-T}^{u}+B^{*}(L) \varepsilon_{t-T}^{b} \\
\sigma^{2}=\operatorname{var}_{t}\left(s_{t+1}\right)=a_{1}^{2} \sigma_{u}^{2}+b_{1}^{2} \sigma_{b}^{2}+\theta^{\prime} \operatorname{var}_{t}\left(\xi_{t}\right) \theta
\end{gathered}
$$

We need to estimate the conditional expectation and variance of the unobservable $\xi_{t}$ as a function of past innovations.

\section{D.2 Conditional moments}

We follow the strategy of Townsend (1983, p.556), but use the notation of Hamilton [1994, chapter 13]. First, we subtract the known components from the observables $s_{t}$ and $v_{t}^{i}$ and define these new variables as $s_{t}^{*}$ and $v_{t}^{i *}$. Let the vector of these

observables be $\mathbf{Y}_{t}^{i}=\left(s_{t}^{*}, s_{t-1}^{*}, \ldots, s_{t-\bar{T}+1}^{*}, v_{t}^{i *}, \ldots, v_{t-\bar{T}+1}^{i *}\right)$. From (44) and (10), we can write:

$$
\mathbf{Y}_{t}^{i}=\mathbf{H}^{\prime} \xi_{t}+\mathbf{w}_{t}^{i}
$$

where $\mathbf{w}_{t}^{i}=\left(0, \ldots, 0, \varepsilon_{t}^{v i}, \ldots, \varepsilon_{t-T+1}^{v i}\right)^{\prime}$ and

$$
\mathbf{H}^{\prime}=\left[\begin{array}{cccccccc}
a_{1} & a_{2} & \ldots & a_{T} & b_{1} & b_{2} & \ldots & b_{T} \\
0 & a_{1} & \ldots & a_{T-1} & 0 & b_{1} & \ldots & b_{T-1} \\
\ldots & \ldots & \ldots & \ldots & \ldots & \ldots & \ldots & \ldots \\
0 & 0 & \ldots & a_{1} & 0 & 0 & \ldots & b_{1} \\
d_{1} & d_{2} & \ldots & d_{T} & 0 & 0 & \ldots & 0 \\
0 & d_{1} & \ldots & d_{T-1} & 0 & 0 & \ldots & 0 \\
\ldots & \ldots & \ldots & \ldots & \ldots & \ldots & \ldots & \ldots \\
0 & 0 & 0 & d_{1} & 0 & 0 & \ldots & 0
\end{array}\right]
$$

The unconditional means of $\xi_{t}$ and $\mathbf{w}_{t}^{i}$ are zero. Define their unconditional variances as $\widetilde{\mathbf{P}}$ and $\mathbf{R}$. Then we have (applying eqs. (17) and (18) in Townsend):

$$
E_{t}^{i}\left(\xi_{t}\right)=\mathbf{M Y}_{t}^{i}
$$


where:

$$
\mathbf{M}=\widetilde{\mathbf{P}} \mathbf{H}\left[\mathbf{H}^{\prime} \widetilde{\mathbf{P}} \mathbf{H}+\mathbf{R}\right]^{-1}
$$

Moreover, $\mathbf{P} \equiv \operatorname{var}_{t}\left(\xi_{t}\right)$ is given by:

$$
\mathbf{P}=\widetilde{\mathbf{P}}-\mathbf{M H}^{\prime} \widetilde{\mathbf{P}}
$$

\section{D.3 Solution}

First, $\sigma^{2}$ can easily be derived from (46) and (50). Second, substituting (48) and (47) into (45), and averaging over investors, gives the average expectation in terms of innovations:

$$
\bar{E}_{t}\left(s_{t+1}\right)=\theta^{\prime} \mathbf{M} \mathbf{H}^{\prime} \xi_{\mathbf{t}}+A^{*}(L) \varepsilon_{t-T}^{u}+B^{*}(L) \varepsilon_{t-T}^{b}
$$

We can then substitute $\bar{E}_{t}\left(s_{t+1}\right)$ and $\sigma^{2}$ into (43) so that we have an expression for $s_{t}$ that has the same form as (12). We then need to solve a fixed point problem.

Although $A(L)$ and $B(L)$ are infinite lag operators, we only need to solve a finitely dimensional fixed point problem in the set of parameters $\left(a_{1}, a_{2}, \ldots, a_{T}, b_{1}, \ldots, b_{T+1}\right)$. This can be seen as follows. First, it is easily verified by equating the parameters of the conjectured and equilibrium exchange rate equation for lags $T$ and greater that $b_{T+s+1}=\frac{1+\alpha}{\alpha} b_{T+s}+\gamma \sigma^{2} \rho_{b}^{T+s-1}$ and $a_{T+s+1}=\frac{1+\alpha}{\alpha} a_{T+s}-\frac{1}{\alpha} d_{s}$ for $s \geq 1$. Assuming non-explosive coefficients, the solutions to these difference equations give us the coefficients for lags $T+1$ and greater: $b_{T+1}=-\alpha \gamma \sigma^{2} \rho_{b}^{T} /\left(1+\alpha-\alpha \rho_{b}\right)$, $b_{T+s}=\left(\rho_{b}\right)^{s-1} b_{T+1}$ for $s \geq 2, a_{T+1}=\frac{1+\alpha}{1+\alpha-\rho}$, and $a_{T+s+1}=\frac{1+\alpha}{\alpha} a_{T+s}-\frac{1}{\alpha} d_{s}$ for $s \geq 1$.

The fixed point problem in the parameters $\left(a_{1}, a_{2}, \ldots, a_{T}, b_{1}, \ldots, b_{T+1}\right)$ consists of $2 T+1$ equations. One of them is the $b_{T+1}=-\alpha \gamma \sigma^{2} \rho_{b}^{T} /\left(1+\alpha-\alpha \rho_{b}\right)$. The other $2 T$ equations equate the parameters of the conjectured and equilibrium exchange rate equations up to lag $T-1$. The conjectured parameters $\left(a_{1}, a_{2}, \ldots, a_{T}, b_{1}, \ldots, b_{T+1}\right)$, together with the solution for $a_{T+1}$ above allow us to compute $\theta, \mathbf{H}, \mathbf{M}$ and $\sigma^{2}$, and therefore the parameters of the equilibrium exchange rate equation. We use the Gauss NLSYS routine to solve the $2 T+1$ non-linear equations. A method that works as well (and is more efficient for large $T$ ) is to assume starting values for these parameters, map them into a new set of parameters by solving the equilibrium exchange rate equation, and continue this process until it converges, which is usually the case. 


\section{E Solution method with infinite-horizon investors}

We now describe the method for solving the equilibrium exchange rate in the model with infinite-horizon investors. Asset demand, which follows from the maximization problem (13)-(14), is more complex than in the two-period case. In particular, investors hedge uncertainty about changes in expected future returns. Our solution method is approximate, based on truncating information after $\bar{T}$ periods. We proceed in six steps: i) we conjecture an exchange rate equation; ii) we derive the expectations of $\mathbf{u}_{t}$ and $b_{t}$ with a Kalman filter, using the conjectured exchange rate equation; iii) we compute the asset demand based on these expectations; iv) we find the equilibrium exchange rate that clears the foreign exchange market; v) we discuss the numerical method used to equate the conjectured exchange rate equation to the one that solves the foreign exchange market equilibrium; vi) we report some numerical results for the benchmark parameterization and compare it to the two-period model.

\section{E.1 The exchange rate equation}

We conjecture the following equilibrium exchange rate equation

$$
s_{t}=\lambda_{s} \mathbf{s}_{t-1}+\lambda_{f} \mathbf{f}_{t}+\lambda_{u} \mathbf{u}_{t}+\lambda_{b} b_{t}
$$

Our solution method relies on truncating at sufficiently large lags $\bar{T}$, so that

$$
\begin{aligned}
\mathbf{s}_{t-1} & =\left(s_{t-1}, s_{t-2}, \ldots, s_{t-\bar{T}}\right)^{\prime} \quad \lambda_{s}=\left(\lambda_{s}^{1}, \lambda_{s}^{2}, \ldots, \lambda_{s}^{\bar{T}}\right) \\
\mathbf{f}_{t} & =\left(f_{t}, f_{t-1}, f_{t-2}, \ldots, f_{t-\bar{T}}\right)^{\prime} \quad \lambda_{f}=\left(\lambda_{f}^{0}, \lambda_{f}^{1}, \ldots, \lambda_{f}^{\bar{T}}\right) \\
\mathbf{u}_{t} & =\left(u_{t}, u_{t-1}, u_{t-2}, \ldots, u_{t-T+1}\right)^{\prime} \quad \lambda_{u}=\left(\lambda_{u}^{0}, \lambda_{u}^{1}, \ldots, \lambda_{u}^{T-1}\right)
\end{aligned}
$$

There are only $T-1$ lags for $u_{t}$ since $u_{t-T}=f_{t}$ after $T$ periods.

\section{E.2 Kalman Filter}

We adopt a notation similar to Hamilton [1994, chapter 13]. Similarly to the two-period case, let $\mathbf{Y}_{t}^{i}$ be a vector of observable variables (present and past) for investor $i$ and $\xi_{t}$ be a vector of unobservables. The components of these vectors 
are however different than in the two-period model. The objective is to determine the estimate of unobservables based on a linear combination of observables, i.e., $E_{t}^{i}\left(\xi_{t}\right)=\mathbf{A} \mathbf{Y}_{t}^{i}$. In this case, the vectors of observables and unknowns are

$$
\mathbf{Y}_{t}^{i}=\left(s_{t}, f_{t}, v_{t}^{i}, s_{t-1}, f_{t-1}, v_{t-1}^{i}, \ldots, s_{t-\bar{T}}, f_{t-\bar{T}}, v_{t-\bar{T}}^{i}\right)^{\prime} \quad \xi_{t}=\left(u_{t}, u_{t-1}, \ldots, u_{t-T}, b_{t}\right)^{\prime}
$$

We use the following linear state-pace representation:

$$
\begin{aligned}
\mathbf{Z Y}_{t}^{i} & =\mathbf{H}^{\prime} \xi_{t}+\mathbf{w}_{t}^{i} \\
\xi_{t} & =\mathbf{F} \xi_{t-1}+\varepsilon_{t}
\end{aligned}
$$

where

$$
\begin{aligned}
& \mathbf{w}_{t}^{i}=\left(0,0, \varepsilon_{t}^{v, i}\right)^{\prime} \quad \varepsilon_{t}=\left(\varepsilon_{t}^{u}, 0, \ldots, 0, \varepsilon_{t}^{b}\right)^{\prime} \\
& \mathbf{Z}=\left[\begin{array}{cccccccccccccc}
1 & -\lambda_{f}^{0} & 0 & -\lambda_{s}^{1} & -\lambda_{f}^{1} & 0 & \lambda_{s}^{2} & \lambda_{f}^{2} & 0 & \ldots & \ldots & b_{s}^{T} & b_{f}^{\bar{T}} & 0 \\
0 & 1 & 0 & 0 & 0 & 0 & 0 & 0 & 0 & \ldots & \ldots & 0 & 0 & 0 \\
0 & 0 & 1 & 0 & 0 & 0 & 0 & 0 & 0 & \ldots & \ldots & 0 & 0 & 0
\end{array}\right] \\
& \mathbf{H}^{\prime}=\left[\begin{array}{ccccccc}
\lambda_{u}^{0} & \lambda_{u}^{1} & \lambda_{u}^{2} & \ldots & \lambda_{T-1}^{u} & 0 & \lambda^{b} \\
0 & 0 & 0 & \ldots & 0 & 1 & 0 \\
1 & 0 & 0 & \ldots & 0 & 0 & 0
\end{array}\right] \quad \mathbf{F}=\left[\begin{array}{ccccccc}
1 & 0 & 0 & \ldots & 0 & 0 & 0 \\
0 & 1 & 0 & \ldots & 0 & 0 & 0 \\
\ldots & \ldots & \ldots & \ldots & \ldots & \ldots & \ldots \\
0 & 0 & 0 & \ldots & 1 & 0 & 0 \\
0 & 0 & 0 & \ldots & 0 & 0 & \rho_{b}
\end{array}\right]
\end{aligned}
$$

The first row of (52) represents the exchange rate equation (51), the second row $u_{t-T}=f_{t}$, and the third row the private signal (10).

We also define the variance-covariance matrices:

$$
\mathbf{R} \equiv \operatorname{var}\left(\mathbf{w}_{t}^{i}\right)=\left[\begin{array}{ccc}
0 & 0 & 0 \\
0 & 0 & 0 \\
0 & 0 & \sigma_{v}^{2}
\end{array}\right] \quad \mathbf{Q} \equiv \operatorname{var}\left(\varepsilon_{t}\right)=\left[\begin{array}{ccccc}
\sigma_{v}^{2} & 0 & \ldots & 0 & 0 \\
0 & 0 & \ldots & 0 & 0 \\
\ldots & \ldots & \ldots & \ldots & \ldots \\
0 & 0 & \ldots & 0 & 0 \\
0 & 0 & \ldots & 0 & \sigma_{b}^{2}
\end{array}\right]
$$

Define the conditional variance-covariance matrices of $\xi_{t}$ in the steady state as $\mathbf{P}=\operatorname{var}\left(\xi_{t} \mid \mathbf{I}_{t}\right)$ and $\widetilde{\mathbf{P}}=\operatorname{var}\left(\xi_{t} \mid \mathbf{I}_{t-1}\right)$, where $\mathbf{I}_{t}$ and $\mathbf{I}_{t-1}$ represent the information available at $t$ and $t-1$. From Hamilton eq. (13.2.15), we have:

$$
E_{t}^{i}\left(\xi_{t}\right)=E_{t-1}^{i}\left(\xi_{t}\right)+\mathbf{M}\left[\mathbf{Z} \mathbf{Y}_{t}^{i}-\mathbf{H}^{\prime} E_{t-1}^{i}\left(\xi_{t}\right)\right]
$$


where $\mathbf{M}$ and $\mathbf{P}$ are defined by (49) and (50) and:

$$
\widetilde{\mathbf{P}}=\mathbf{F P F}^{\prime}+\mathbf{Q}
$$

We need to solve for the matrix $\mathbf{A}$ in $E_{t}^{i}\left(\xi_{t}\right)=\mathbf{A} \mathbf{Y}_{t}^{i}$. Using $E_{t-1}^{i}\left(\xi_{t}\right)=$ $\mathbf{F} E_{t-1}^{i}\left(\xi_{\mathbf{t}-\mathbf{1}}\right)$ from $(53)$, (54) gives:

$$
\begin{aligned}
\mathbf{A Y}_{t}^{i}= & \mathbf{F A Y}_{t-1}^{i}+\mathbf{M Z Y}_{t}^{i}-\mathbf{M H}^{\prime} \mathbf{F A Y}_{t-1}^{i}= \\
& \mathbf{M Z Y}_{t}^{i}+\left[\mathbf{F A}-\mathbf{M H}^{\prime} \mathbf{F A}\right] \mathbf{Y}_{t-1}^{i}
\end{aligned}
$$

We set $\bar{T}$ sufficiently large such that the last 3 columns of $\mathbf{A}$ are negligible (less that $10^{-5}$ ). Thus, we can set the last 3 elements of $\mathbf{Y}_{t-1}^{i}$ to zero in the above equation. Define $\widetilde{\mathbf{Y}}_{t-1}^{i}$ as $\mathbf{Y}_{t-1}^{i}$ with the last 3 elements set equal to zero. We then define a transformation matrix $\mathbf{U}$ such that $\widetilde{\mathbf{Y}}_{t-1}^{i}=\mathbf{U} \mathbf{Y}_{t}^{i}$, so that (56) implies:

$$
\mathbf{A}=\mathbf{M Z}+\mathbf{F A U}-\mathbf{M H}^{\prime} \mathbf{F A U}
$$

The matrices $\mathbf{P}, \tilde{\mathbf{P}}$ and $\mathbf{A}$ can be solved from (50), (55) and (57) for a given exchange rate equation.

\section{E.3 Optimal asset demand}

The analysis here draws on Wang [1994, Appendix A]. Investor $i$ maximizes (13) subject to (14). The Bellman equation is

$$
U_{t}^{i}=\max \left\{-e^{-\gamma c_{t}^{i}}+\beta E_{t} U_{t+1}^{i}\right\}
$$

where the maximization is done with respect to $c_{t}^{i}$ and $b_{t}^{i}$. We conjecture that the value function is:

$$
U_{t}^{i}=-\alpha_{1} \exp \left\{-\alpha_{2} w_{t}^{i}-\frac{1}{2} \mathbf{Y}_{t}^{i} \mathbf{V} \mathbf{Y}_{t}^{i \prime}\right\}
$$

Define the excess return on foreign bonds as $q_{t+1}=s_{t+1}-s_{t}+i_{t}^{*}-i_{t}$. Then using (14) we have:

$U_{t+1}^{i}=-\alpha_{1} \exp \left\{-\alpha_{2}\left(1+i_{t}\right) w_{t}^{i}+\alpha_{2} c_{t}^{i}-\alpha_{2}\left[f\left(\tilde{m}_{t}^{i}\right)-i_{t} \tilde{m}_{t}^{i}\right]-\alpha_{2} b_{t}^{i} q_{t+1}-\frac{1}{2} \mathbf{Y}_{t+1}^{i} \mathbf{V} \mathbf{Y}_{t+1}^{i \prime}\right\}$ 
Maximization over $\tilde{m}_{t}^{i}$ gives $f^{\prime}\left(\tilde{m}_{t}^{i}\right)=i_{t}$, which leads to the same aggregate money demand function as before. Since $i_{t}=r$ is constant, the term $-\alpha_{2}\left[f\left(\tilde{m}_{t}^{i}\right)-i_{t} \tilde{m}_{t}^{i}\right]$ is a constant, which we will denote $K$ below.

We now want to express the last two terms of (59) as a function of current observables $\mathbf{Y}_{t}^{i}$. Using $i_{t}^{*}-i_{t}=\left(f_{t}-s_{t}\right) / \alpha$, we get:

$$
q_{t+1}=s_{t+1}-\frac{1+\alpha}{\alpha} s_{t}+\frac{f_{t}}{\alpha}
$$

We can then use (51) to substitute for $s_{t+1}$. We decompose $q_{t+1}$ into expected and unexpected components. Let us define the vector of shocks $\epsilon_{t+1}^{i}=\left(\varepsilon_{t+1}^{u}, \varepsilon_{t+1}^{v i}, \varepsilon_{t+1}^{b}, \widetilde{\xi}_{t}-\right.$ $\left.E_{t}^{i}\left(\widetilde{\xi}_{t}\right)\right)^{\prime}$ and $\widetilde{\xi}_{t}=\left(u_{t}, u_{t-1}, \ldots, u_{t-T+1}\right)^{\prime}$. After a few substitutions we get:

$$
q_{t+1}=\Theta_{1}^{\prime} \mathbf{Y}_{t}^{i}+\Theta_{2}^{\prime} E_{t}^{i}\left(\xi_{t}\right)+\Theta_{3}^{\prime} \epsilon_{t+1}^{i}
$$

Since $E_{t}^{i}\left(\xi_{t}\right)=\mathbf{A} \mathbf{Y}_{t}^{i}$, we get:

$$
q_{t+1}=\Theta^{\prime} \mathbf{Y}_{t}^{i}+\Theta_{3}^{\prime} \epsilon_{t+1}^{i}
$$

where $\Theta \equiv \Theta_{1}+\mathbf{A}^{\prime} \Theta_{2}$.

Similarly to $q_{t+1}$ we can express $s_{t+1}, f_{t+1}$, and $v_{t+1}^{i}$ as functions of $\mathbf{Y}_{\mathbf{t}}^{\mathbf{i}}$ and $\epsilon_{t+1}^{i}$. This allows us to express $\mathbf{Y}_{t+1}^{i}$ in terms of $\mathbf{Y}_{t}^{i}$ and $\epsilon_{t+1}^{i}$ :

$$
\mathbf{Y}_{t+1}^{i}=\mathbf{N}_{\mathbf{1}} \mathbf{Y}_{t}^{i}+\mathbf{N}_{\mathbf{2}} \epsilon_{t+1}^{i}
$$

We can then rewrite (59) as:

$$
U_{t+1}^{i}=-\alpha_{1} \exp \left\{\begin{array}{c}
-\alpha_{2}\left(1+i_{t}\right) w_{t}^{i}+\alpha_{2} c_{t}^{i}-\alpha_{2} b_{t}^{i} \Theta^{\prime} \mathbf{Y}_{t}^{i}-\frac{1}{2} \mathbf{Y}_{t}^{i \prime} \mathbf{N}_{1}^{\prime} \mathbf{V} \mathbf{N}_{1} \mathbf{Y}_{t}^{i} \\
-\alpha_{2} b_{t}^{i} \Theta_{3}^{\prime} \epsilon_{t+1}^{i}-\mathbf{Y}_{t}^{i \prime} \mathbf{N}_{1}^{\prime} \mathbf{V} \mathbf{N}_{\mathbf{2}} \epsilon_{t+1}^{i}-\frac{1}{2} \epsilon_{t+1}^{\prime} \mathbf{N}_{\mathbf{2}}^{\prime} \mathbf{V} \mathbf{N}_{\mathbf{2}} \epsilon_{t+1}^{i}+K
\end{array}\right\}
$$

Using the normality of the random variables in $\epsilon_{t+1}^{i}$ :

$$
E_{t}^{i}\left(U_{t+1}^{i}\right)=\frac{-\alpha_{1}}{|\Sigma|^{\frac{1}{2}}|\Omega|^{-\frac{1}{2}}} \exp \left\{\begin{array}{c}
-\alpha_{2}\left(1+i_{t}\right) w_{t}^{i}+\alpha_{2} c_{t}^{i}-\alpha_{2} b_{t}^{i} \Theta^{\prime} \mathbf{Y}_{t}^{i}-\frac{1}{2} \mathbf{Y}_{t}^{i \prime} \mathbf{N}_{1}^{\prime} \mathbf{V N}_{\mathbf{1}} \mathbf{Y}_{t}^{i} \\
+\frac{1}{2} \alpha_{2}^{2} b_{t}^{i 2} \Theta_{3}^{\prime} \Omega \Theta_{3}+\mathbf{Y}_{t}^{i \prime} \mathbf{N}_{1}^{\prime} \mathbf{V N}_{\mathbf{2}} \Omega \mathbf{N}_{2}^{\prime} \mathbf{V}^{\prime} \mathbf{N}_{1} \mathbf{Y}_{t}^{i} \\
+2 \alpha_{2} b_{t}^{i} \Theta_{3}^{\prime} \Omega \mathbf{N}_{2}^{\prime} \mathbf{V}^{\prime} \mathbf{N}_{1} \mathbf{Y}_{t}^{i}+K
\end{array}\right\}
$$

where $\Sigma=\operatorname{var}\left(\epsilon_{t+1}^{i}\right)$ and $\Omega=\left[\Sigma^{-1}+\mathbf{N}_{\mathbf{2}}^{\prime} \mathbf{V N}_{\mathbf{2}}\right]^{-1}$. Maximizing this expression with respect to $b_{t}^{i}$, we get

$$
b_{t}^{i}=\frac{\left[\Theta^{\prime}-\Theta_{3}^{\prime} \Omega \mathbf{N}_{\mathbf{2}}^{\prime} \mathbf{V}^{\prime} \mathbf{N}_{1}\right] \mathbf{Y}_{t}^{i}}{\alpha_{2} \Theta_{3}^{\prime} \Omega \Theta_{3}}
$$


The first term in brackets represents the expected return, while the second term represents the hedge against expected return changes.

After maximizing the Bellman equation with respect to $c_{t}^{i}$ and substituting the result back into the Bellman equation, it is easily verified that our conjecture of the value function (59) is correct if $\alpha_{2}=\gamma r$ and

$\mathbf{V}=\frac{1}{1+r}\left(\frac{\left(\Theta-\mathbf{N}_{1}^{\prime} \mathbf{V} \mathbf{N}_{2} \Omega^{\prime} \Theta_{3}\right)\left(\Theta^{\prime}-\Theta_{3}^{\prime} \Omega \mathbf{N}_{2}^{\prime} \mathbf{V} \mathbf{N}_{1}\right)}{\Theta_{3}^{\prime} \Omega \Theta_{3}}+\mathbf{N}_{1}^{\prime} \mathbf{V} \mathbf{N}_{1}-\mathbf{N}_{1}^{\prime} \mathbf{V} \mathbf{N}_{2} \Omega \mathbf{N}_{2}^{\prime} \mathbf{V}^{\prime} \mathbf{N}_{1}\right)$

This contains an implicit solution for $\mathbf{V}$.

\section{E.4 Foreign exchange market equilibrium}

Foreign exchange market equilibrium implies $\int_{0}^{1} b_{t}^{i}=b_{t}$, where $b_{t}$ is total supply associated with non-fundamentals based trade. Aggregating (65), this implies

$$
\alpha_{2} \Theta_{3}^{\prime} \Omega \Theta_{3} b_{t}=\omega^{\prime} \mathbf{Y}_{t}
$$

where $\mathbf{Y}_{t}$ is the average $\mathbf{Y}_{t}^{i}$ (i.e., $v_{t}^{i}, v_{t-1}^{i}, .$. are replaced by $u_{t}, u_{t-1}, \ldots$ ) and the vector $\omega$ is defined as:

$$
\omega=\Theta-\mathbf{N}_{1}^{\prime} \mathbf{V N}_{2} \Omega \Theta_{3} .
$$

Equation (67) can be solved for the equilibrium exchange rate:

$$
s_{t}=\lambda_{s}^{\prime} \mathbf{s}_{t-1}+\lambda_{f}^{\prime} \mathbf{f}_{t}+\lambda_{u}^{\prime} \mathbf{u}_{t}+\lambda_{b}^{\prime} b_{t}
$$

with the parameters a function of $\alpha_{2} \Theta_{3}^{\prime} \Omega \Theta_{3}$ and $\omega$.

\section{E.5 Numerical Solution}

In order to solve for the exchange rate equation, we need to simultaneously solve for the matrices $\mathbf{A}, \mathbf{P}, \widetilde{\mathbf{P}}, \mathbf{V}$, the vectors $\lambda_{f}, \lambda_{u}, \lambda_{s}$, and $\lambda_{b}$. This is done as follows. For a given $\mathbf{V}$ we solve for all the other parameters with the Gauss nonlinear equation system routine NLSYS. The equations solved are (50), (55), (57), $\lambda_{f}=\lambda_{f}^{\prime}, \lambda_{s}=\lambda_{s}^{\prime}, \lambda_{u}=\lambda_{u}^{\prime}$ and $\lambda_{b}=\lambda_{b}^{\prime}$. We start with $\mathbf{V}=0$ and solve for the other parameters. Given the other parameters we then solve for $\mathbf{V}$ using (66). The 
solution to (66) is found as follows. We first set $\mathbf{V}=\mathbf{0}$ on the right hand side. The expression then gives us a new $\mathbf{V}$ on the left hand side. We then substitute this on the right hand side, and so on, until it converges to the solution. Once we obtain the solution of $\mathbf{V}$ to (66), we use the NLSYS routine to solve again for the other parameters. After that we compute a new $\mathbf{V}$ from (66), and so on, until the process converges (with changes in parameters becoming negligibly small from one iteration to the next).

\section{E.6 Infinite Horizon Results}

The results for the infinite horizon model are practically identical to those for the overlapping generations model. In order to illustrate this, we report some results based on the benchmark parameterization. Two points need to be made about parameter choices. First, the $\gamma$ in the infinite horizon model is not exactly the same as the $\gamma$ in the overlapping generations model. In the infinite horizon model $\alpha_{2}=$ $\gamma r$ is the rate of absolute risk-aversion with respect to wealth, which is comparable to the absolute risk-aversion parameter $\gamma$ in the overlapping generations model. We therefore set $\alpha_{2}$ to the same value as $\gamma$ in the overlapping generations model. Second, a solution to (66) requires us to set the real interest rate $r$. We set it at 0.01, although results are not sensitive to this.

The magnification factor of the impact of $b$-shocks on the exchange rate is 7.2328 for the overlapping generations model and 7.3225 for the infinite horizons model. The contribution of $b$-shocks to $\operatorname{var}\left(s_{t+1}-s_{t}\right)$ is $69.37 \%$ for the overlapping generations model and $68.67 \%$ for the infinite horizon model. Finally, the halflife of the impact of $b$-shocks on the exchange rate is 2.9522 for the overlapping generations model and 2.9275 for the infinite horizon model. 


\section{References}

[1] Allen, Franklin, Stephen Morris, and Hyun Song Shin (2003), "Beauty Contests, Bubbles and Iterated Expectations in Asset Markets," mimeo.

[2] Brown, David P., and Robert H. Jennings (1989), "On Technical Analysis," Review of Financial Studies 2, 527-552.

[3] Brunnermeier, Markus K. (2001), Asset Pricing under Asymmetric Information, Oxford University Press, (Oxford).

[4] Cheung, Yin-Wong, Menzie D. Chinn and Antonio G. Pascual (2002), "Empirical Exchange Rate Models of the Nineties: Are they Fit to Survive?" NBER WP. 9393.

[5] Chinn, Menzie D., and Richard A. Meese (1995), "Banking on Currency Forecasts: How Predictable is Change in Money?," Journal of International Economics 38, 161-178.

[6] Chionis, Dionysios, and Ronald MacDonald (2002), "Aggregate and Disaggregate Measures of the Foreign Exchange Risk Premium," International Review of Economics and Finance 11, 57-84.

[7] Devereux, Michael B., and Charles Engel (2002), "Exchange Rate Passthrough, Exchange Rate Volatility, and Exchange Rate Disconnect," Journal of Monetary Economics 49, 913-940.

[8] Diamond, Douglas W., and Robert E. Verrecchia (1981), "Information Aggregation in a Noisy Rational Expectations Economy," Journal of Financial Economics 9, 221-235.

[9] Dow, James and Gary Gorton (1995), "Profitable Informed Trading in a Simple General Equilibrium Model of Asset Pricing," Journal of Economic Theory 67, pp. 327-369.

[10] Elliot, Graham, and Takatoshi Ito (1999), "Heterogeneous Expectations and Tests of Efficiency in the Yen/Dollar Forward Exchange Rate Market," Journal of Monetary Economics 43, 435-456. 
[11] Engel, Charles, and Kenneth D. West (2002), "Exchange Rates and Fundamentals," working paper, University of Wisconsin.

[12] Evans, Martin D. D., and Richard K. Lyons (2002), "Order Flow and Exchange Rate Dynamics," Journal of Political Economy 110, 170-180.

[13] Frankel, Jeffrey A., and Andrew K. Rose (1995), "Empirical Research on Nominal Exchange Rates," in G.M. Grossman and K. Rogoff, eds., Handbook of International Economics, volume III, pp. 1689-1729.

[14] Froot, Kenneth A., and Tarun Ramadorai (2002), "Currency Returns, Institutional Investor Flows, and Exchange Rate Fundamentals," NBER WP No. 9080.

[15] Gennotte, Gerard and Hayne Leland (1990), "Market Liquidity, Hedging and Crashes," The American Economic Review 80(5), pp. 999-1021.

[16] Gourinchas, Pierre-Olivier and Aaron Tornell (2002), "Exchange Rate Dynamics, Learning and Misperception," NBER WP. 9391.

[17] Grossman, Sanford J., and Joseph E. Stiglitz (1980), "On the Impossibility of Informationally Efficient Markets," American Economic Review 70, 393-408.

[18] Grundy, Bruce D. and Maureen McNichols (1989), "Trade and the Revelation of Information through Prices and Direct Disclosure," Review of Financial Studies 2(4), pp. 495-526.

[19] Hau, Harald, and Hélène Rey (2002), "Capital Flows, Exchange Rates, and Asset Prices," NBER WP. 9398.

[20] He, Hua, and Jiang Wang (1995), "Differential Information and Dynamic Behavior of Stock Trading Volume," Review of Financial Studies 8, 919-972.

[21] Hellwig, Martin (1980), "On the Aggregation of Information in Competitive Markets," Journal of Economic Theory 22, 477-498.

[22] Honkapohja, S., and K. Mitra (2002), "Learning Stability in Economics with Heterogeneous Agents," European Central Bank, Working Paper No. 120. 
[23] Ito, Takatoshi (1990), "Foreign Exchange Expectations: Micro Survey Data," American Economic Review 80, 434-449.

[24] Jeanne, Olivier, and Andrew K. Rose (2002), "Noise Trading and Exchange Rate Regimes," Quarterly Journal of Economics 117, May, 537-69.

[25] Kasa, Kenneth (2000), "Forecasting the Forecasts of Others in the Frequency Domain," Review of Economic Dynamics 3, 726-756.

[26] Keynes, John Maynard (1936), The General Theory of Employment, Interest and Money, MacMillan, London.

[27] King, Robert G. (1982), "Monetary Policy and the Information Content of Prices," Journal of Political Economy 90, 247-279.

[28] Kollman, R. (2002), "Monetary Policy Rules in an Interdependent World," mimeo.

[29] Lucas, Robert E. (1972), "Expectations and the Neutrality of Money," Journal of Economic Theory 4, 103-124.

[30] Lyons, Richard K. (2001), The Microstructure Approach to Exchange Rates, MIT Press, (Cambridge, Massachusetts).

[31] MacDonald, Ronald, and Ian W. Marsh (1996), "Currency Forecasters are Heterogeneous: Confirmation and Consequences," Journal of International Money and Finance 15, 665-685.

[32] MacDonald, Ronald and Mark P. Taylor (1993), "The Monetary Approach to the Exchange Rate: Rational Expectations, Long-Run Equilibrium and Forecasting," IMF Staff Papers 40(1), 89-107.

[33] Mankiw, N. Gregory and Ricardo Reis (2002), "Sticky Information versus Sticky Prices: A Proposal to Replace the New Keynesian Phillips Curve," Quarterly Journal of Economics 117(4), pp. 1295-1328.

[34] Mark, Nelson C. (1995), "Exchange Rates and Fundamentals: Evidence on Long-Horizon Predictability," American Economic Review 85, 201-218. 
[35] Mark, Nelson C. and Donggyu Sul (2001), "Nominal Exchange Rates and Monetary Evidence from a Small Post-Bretton Woods Panel," Journal of International Economics 53, 29-52.

[36] Mark, Nelson C. and Yangru Wu (1998), "Rethinking Deviations from Uncovered Interest Parity: The Role of Covariance Risk and Noise," Economic Journal 108, pp. 1686-1706.

[37] Meese, Richard A. and Kenneth Rogoff (1983), "Empirical Exchange Rate Models of the Seventies: Do They Fit Out of Sample?" Journal of International Economics 14, pp. 345-373.

[38] Obstfeld, M., and K. Rogoff (2001), "The Six Major Puzzles in International Macroeconomics: Is There a Common Cause?" in B.S Bernanke, and K. Rogoff (eds.), NBER Macroeconomics Annual 2000, MIT Press 339-390.

[39] Pearlman, Joseph G. and Thomas J. Sargent (2002), "Knowing the Forecasts of Others," mimeo.

[40] Rime, Dagfinn (2001), "Private or Public Information in Foreign Exchange Markets? An Empirical Analysis," mimeo.

[41] Romer, D. (1993), "Rational Asset-Price Movements Without News," American Economic Review 83, 1112-1130.

[42] Sargent, Thomas J. (1991), "Equilibrium with Signal Extraction from Endogenous Variables," Journal of Economic Dynamics and Control 15, 245-273.

[43] Singleton, Kenneth J. (1987), "Asset Prices in a Time-Series Model with Disparately Informed, Competitive Traders", in W.A. Barnett, and K.J. Singleton, eds., New Approaches to Monetary Economics, Cambridge University Press (Cambridge, UK), 249-272.

[44] Spiegel, M. and A. Subrahmanyam (1992), "Informed Speculation and Hedging in a Noncompetitive Securities Market," The Review of Financial Studies 5, 307-329.

[45] Townsend, Robert M. (1983), "Forecasting the Forecasts of Others," Journal of Political Economy 91, 546-588. 
[46] Wang, Jiang (1993), "A Model of Asset Prices under Asymmetric Information," Review of Economic Studies 60(2), pp. 249-282.

[47] Wang, Jiang (1994), "A Model of Competitive Stock Trading Volume," Journal of Political Economy 102, 127-168.

[48] Woodford, Michael (2001), "Imperfect Common Knowledge and the Effects of Monetary Policy," NBER WP No. 8673. 


\begin{tabular}{||l|l||}
\hline \hline & $\begin{array}{l}\text { Benchmark } \\
\text { parameterization }\end{array}$ \\
\hline$\sigma_{b}$ & 0.01 \\
$\sigma_{v}$ & 0.08 \\
$\sigma_{u}$ & 0.01 \\
$\rho$ & 0 \\
$\rho_{b}$ & 0.8 \\
$\alpha$ & 10 \\
$\gamma$ & 500 \\
$T$ & 8 \\
\hline \hline
\end{tabular}

Table 1: Parameterization 


\section{Figure 1 Magnification and relative weight $x$ in model without infinite regress*}

Panel A Magnification Factor

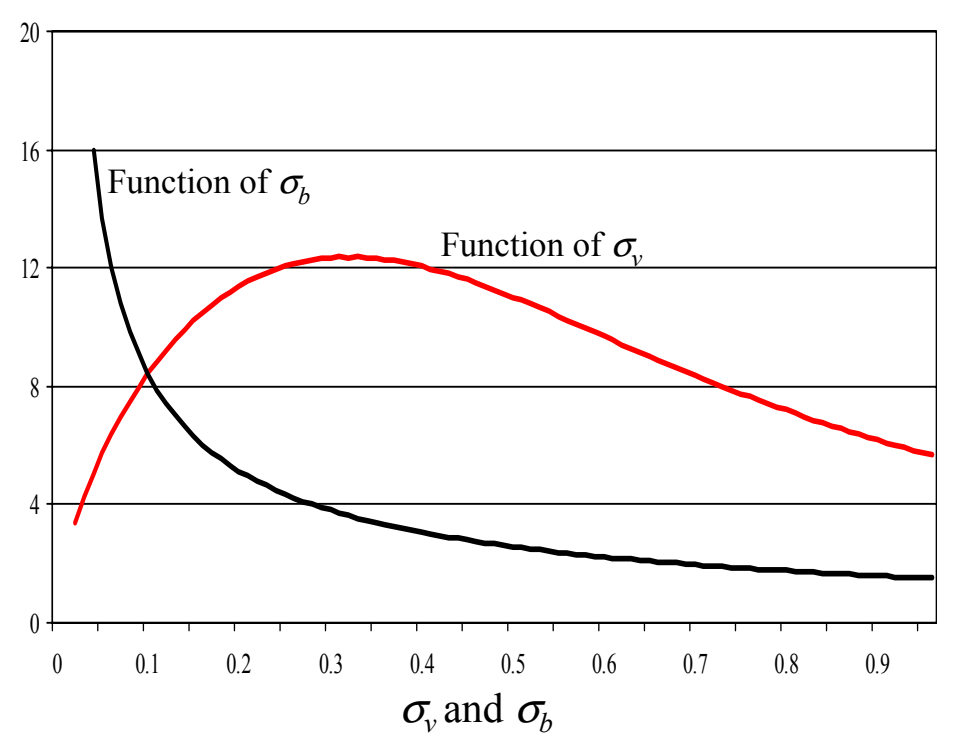

Panel B Relative weight $x=\lambda_{u} / \lambda_{b}$

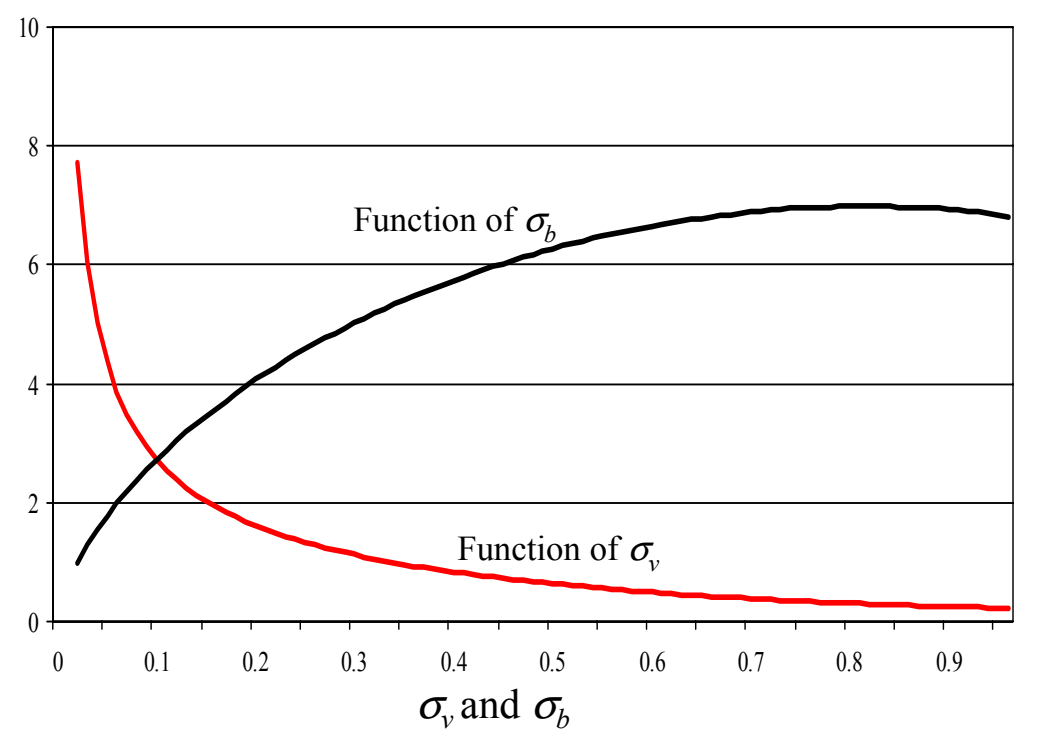

*These figures are based on the simulation of the model for $\mathrm{T}=1, \rho_{1}=\rho_{2}=\rho_{\mathrm{b}}=0$. The qualitative results do not depend on other model parameters. We set $\alpha=10, \gamma=50$, and all standard deviations of the shocks equal to 0.1 , unless varied within the Figure. 


\section{Figure 2 Results for the Benchmark Parameterization*}

Panel A Impulse Response Functions in Heterogeneous Information Model

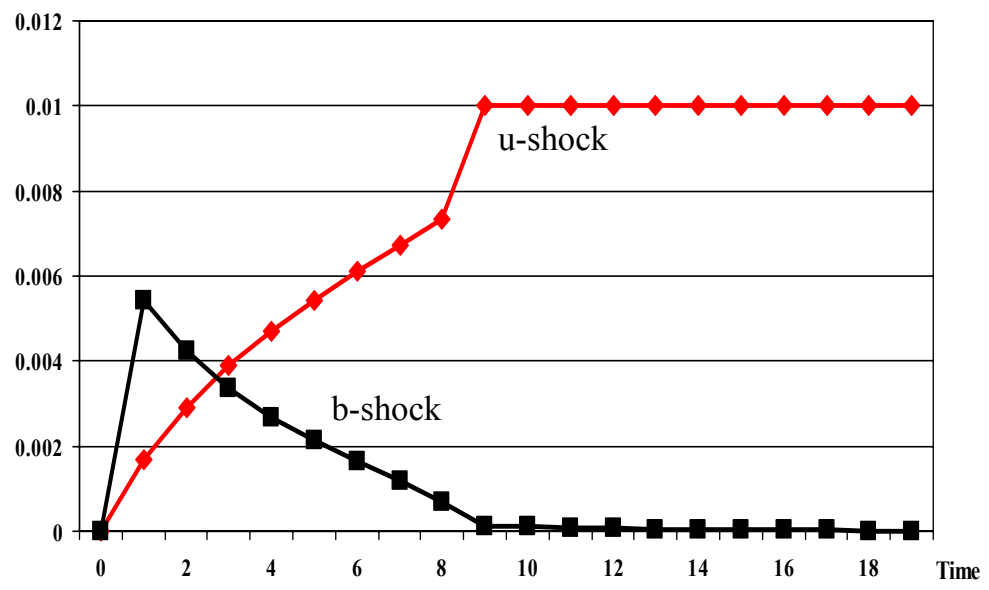

Panel C Percent contribution b-shocks to $\operatorname{var}\left(\mathrm{s}_{\mathrm{t}+\mathrm{k}}-\mathrm{s}_{\mathrm{t}}\right)$

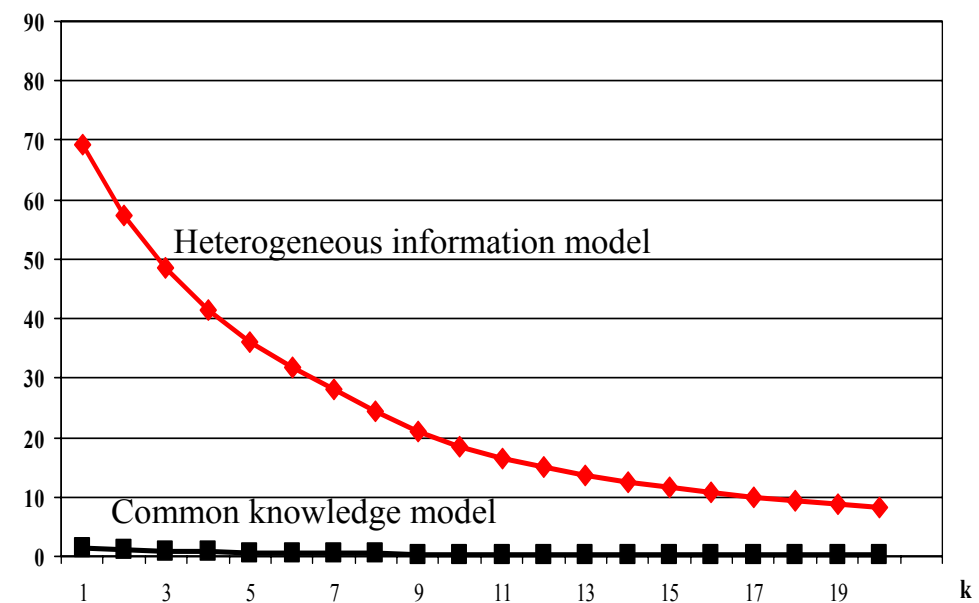

Panel B Impulse Response Functions in Common Knowledge Model

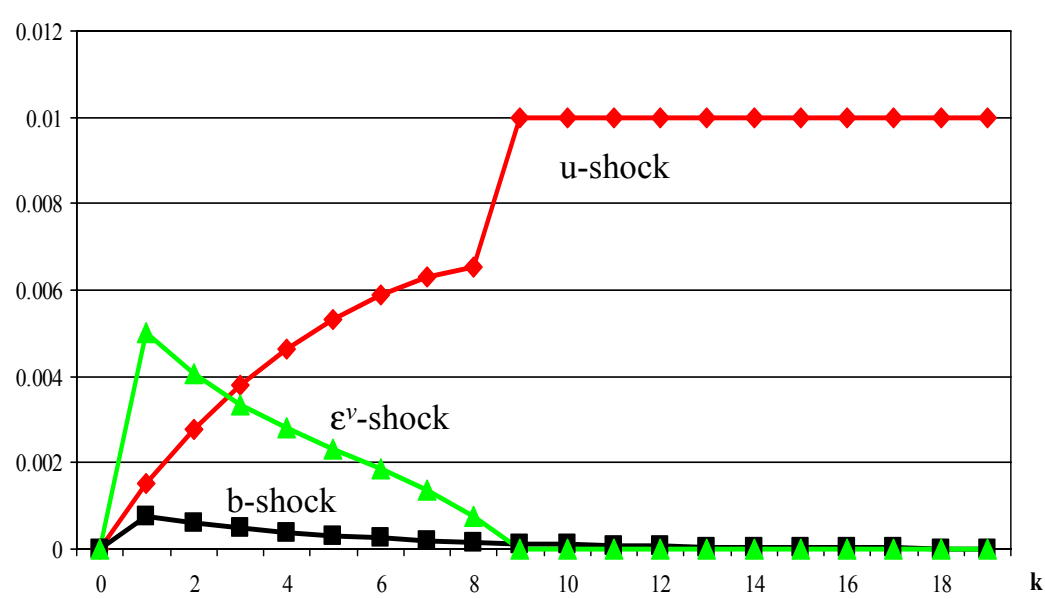

Panel D R $\mathrm{R}^{2}$ of regression of $\mathrm{s}_{\mathrm{t}+\mathrm{k}}-\mathrm{s}_{\mathrm{t}}$ on current and lagged fundamentals

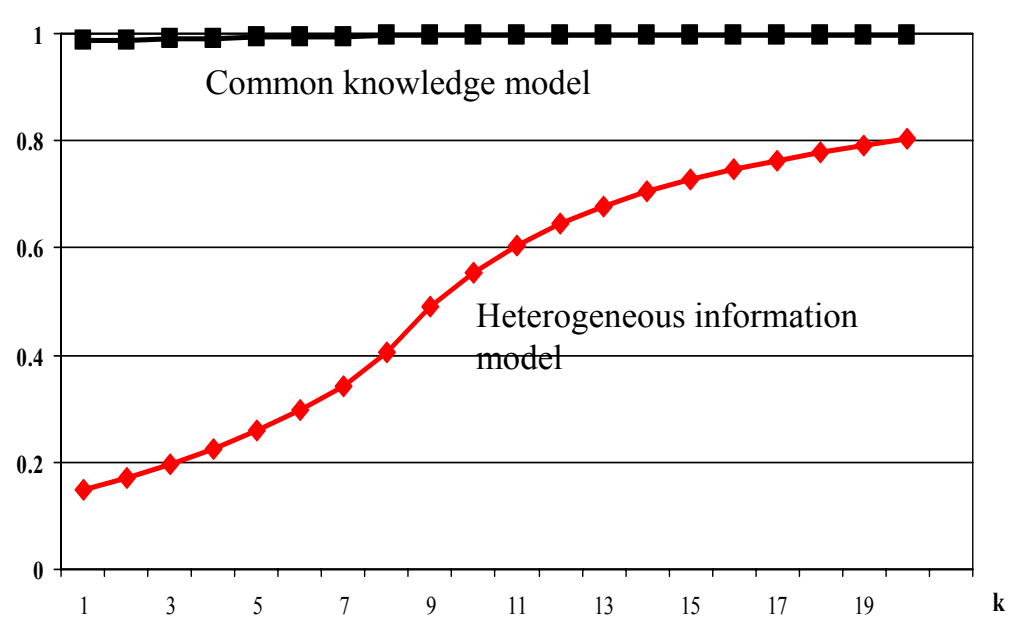

* See Table 1. 
Figure 2 Results for the Benchmark Parameterization-continued.

Panel E $R^{2}$ of regression of $f_{t+k}-f_{t+1}$ on $s_{t+1}-s_{t}$.

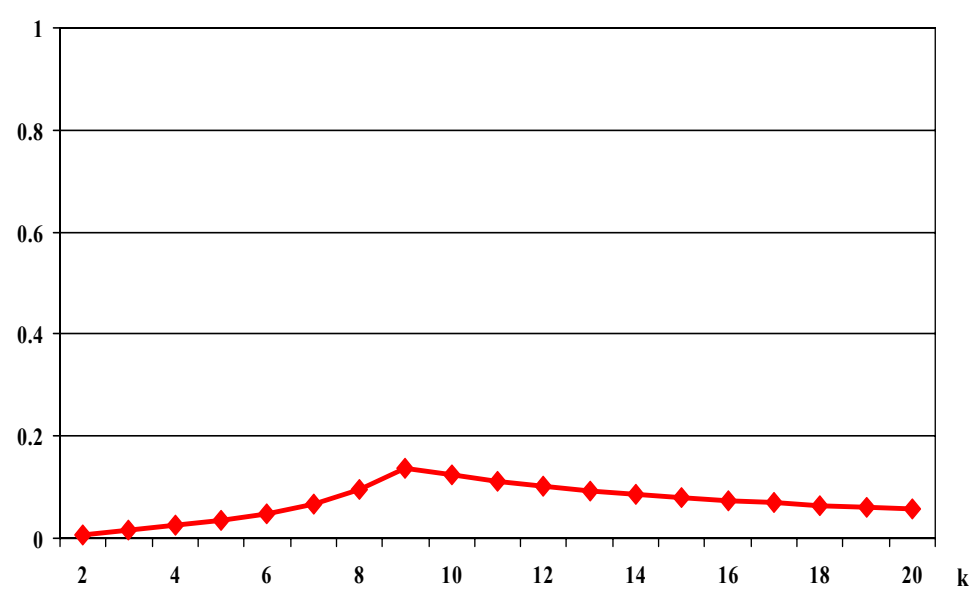




\section{Figure 3 Sensitivity Analysis*}

Panel A Impact of $\sigma$

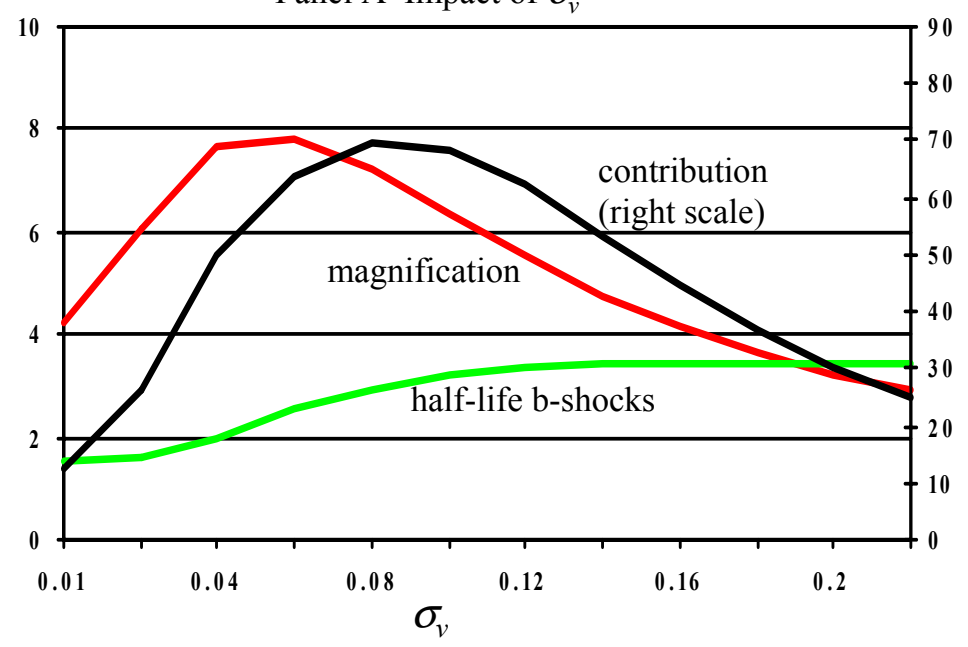

Panel C Impact of $\rho_{b}$

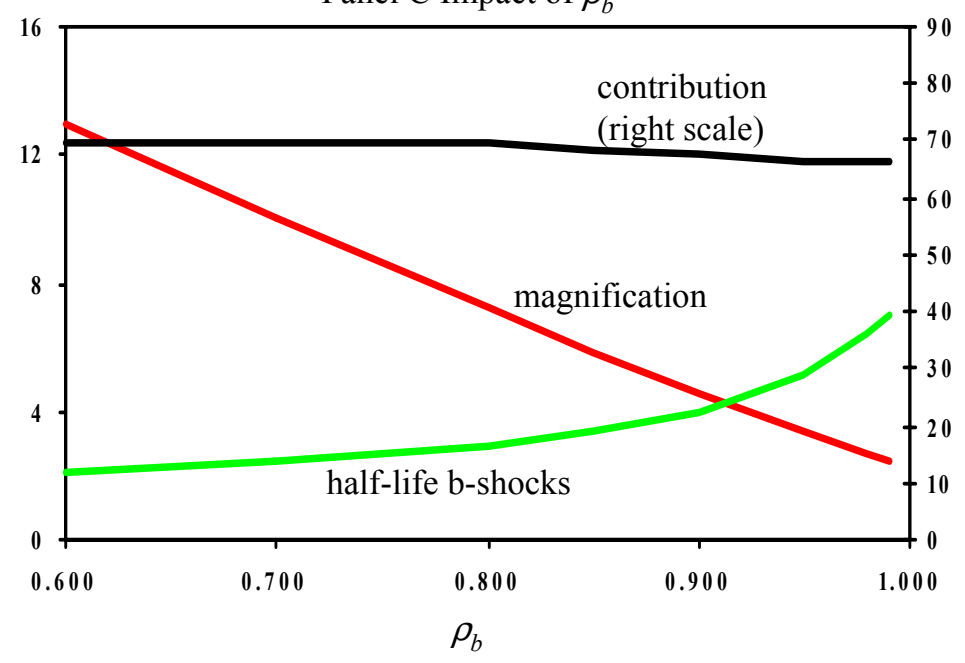

Panel B Impact of $\sigma_{b}$

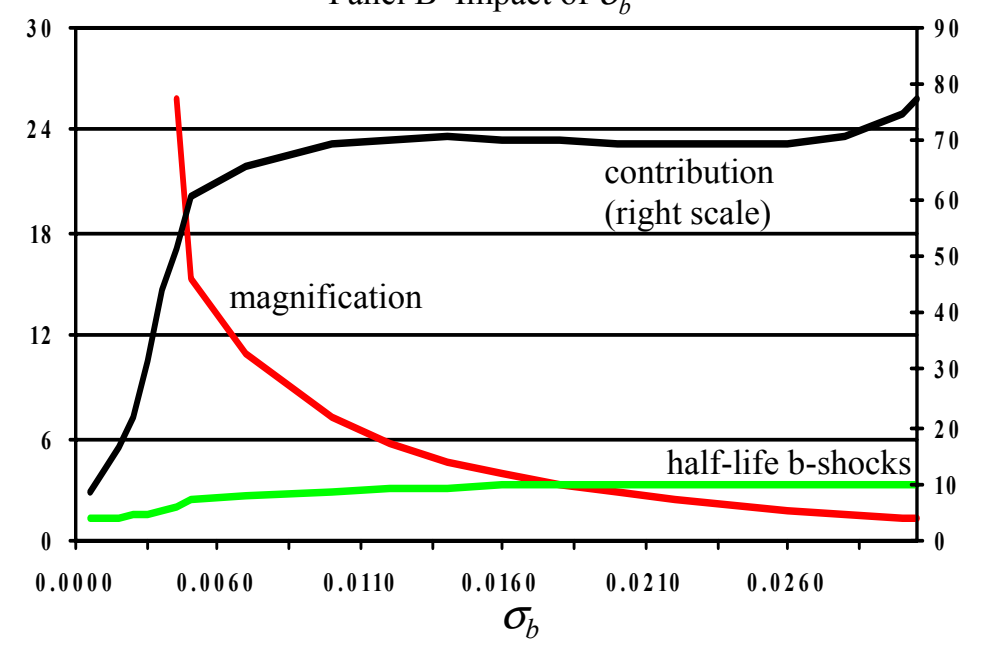

Panel D Impact of $\sigma_{u}$

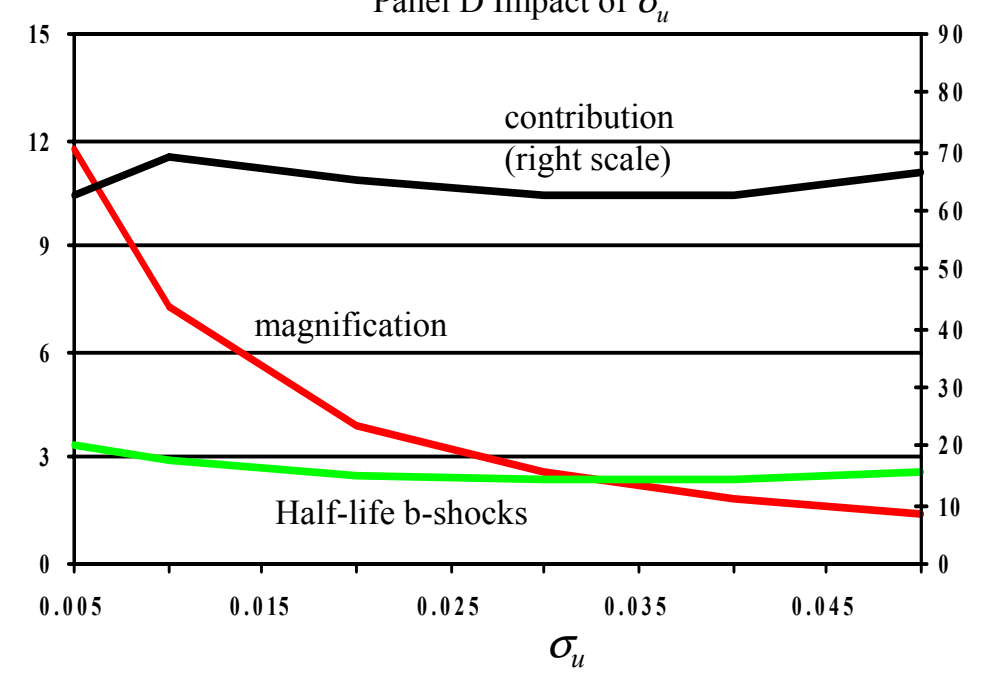

* Contribution $=$ the percentage of $\operatorname{var}\left(\mathrm{s}_{\mathrm{t}+1}-\mathrm{s}_{\mathrm{t}}\right)$ contributed by non-fundamental shocks (b-shocks). It is measured in percentage terms on the right scale. Magnification = factor by which information dispersion amplifies the exchange rate response to b-shocks (measured on the left scale). Half life $=$ number of periods after which the impact of a b-shock on the exchange rate is reduced by half relative to the initial impact (measured on the left scale). 


\section{Figure 3 Sensitivity Analysis-continued*}

Panel E Impact of $\rho$

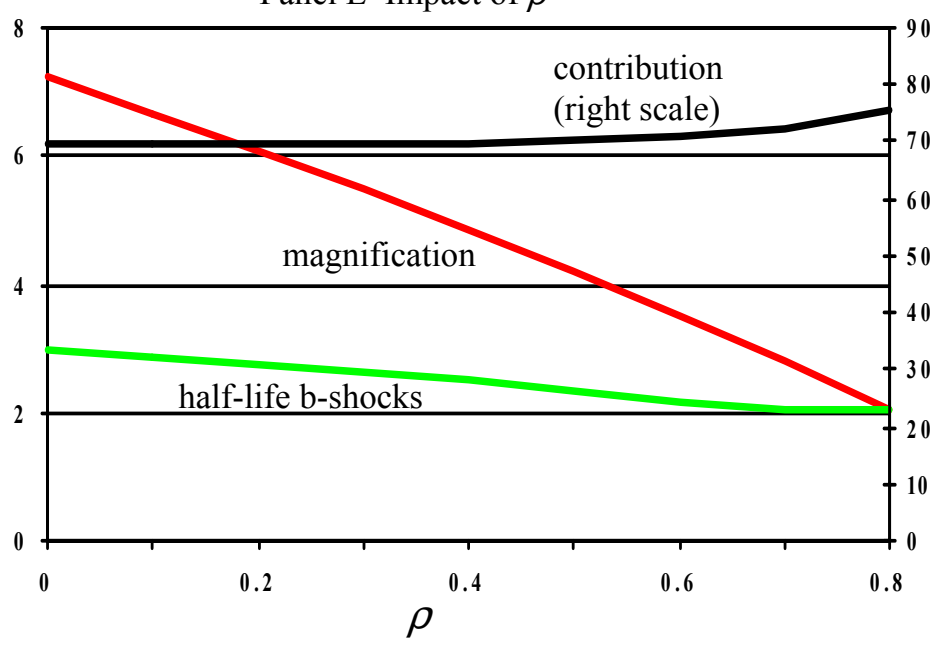

Panel G Impact of $\alpha$

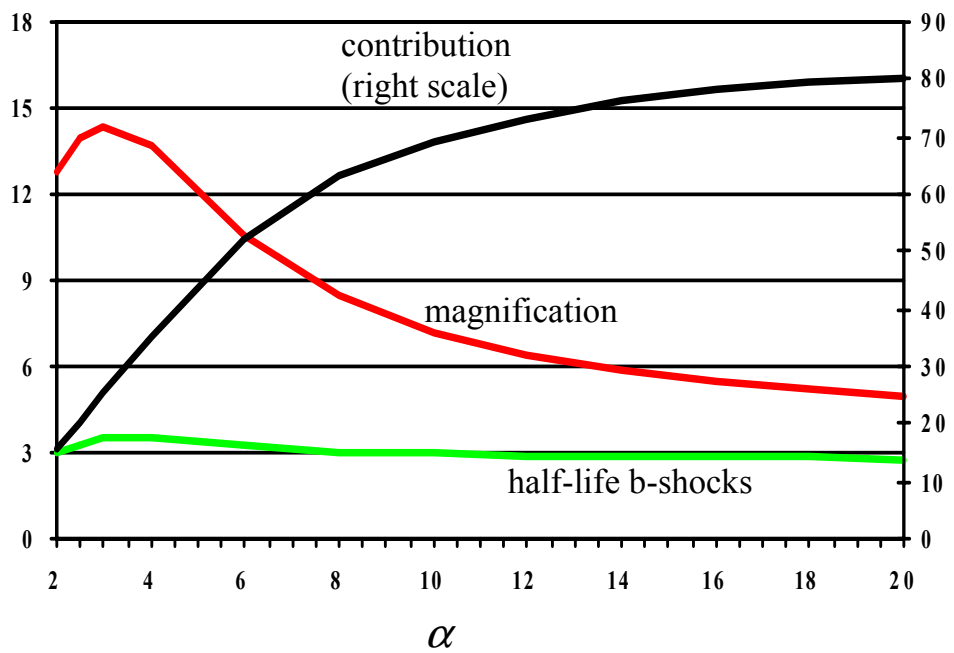

Panel F Impact of $T$

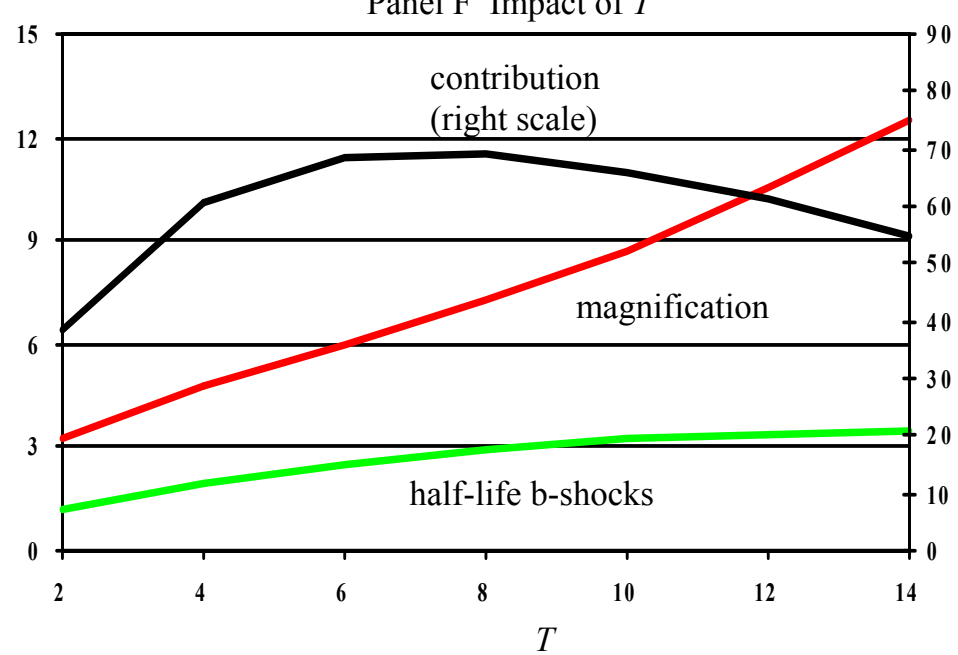

* Contribution $=$ the percentage of $\operatorname{var}\left(\mathrm{s}_{t+1}-\mathrm{s}_{\mathrm{t}}\right)$ contributed by non-fundamental shocks (b-shocks). It is measured in percentage terms on the right scale. Magnification = factor by which information dispersion amplifies the exchange rate response to b-shocks (measured on the left scale). Half life $=$ number of periods after which the impact of a b-shock on the exchange rate is reduced by half relative to the initial impact (measured on the left scale). 